\title{
Expansion of the Metrological Visualization Capability by the Implementation of Acoustic Emission Analysis
}

\author{
Philipp Bergmann, Florian Grün, Florian Summer, István Gódor, and Gabriel Stadler
}

Chair of Mechanical Engineering, Montanuniversität Leoben, Franz-Josef-Straße 18, 8700 Leoben, Austria

Correspondence should be addressed to Philipp Bergmann; philipp.bergmann@unileoben.ac.at

Received 2 February 2017; Revised 8 May 2017; Accepted 4 June 2017; Published 1 August 2017

Academic Editor: Michel Fillon

Copyright (C) 2017 Philipp Bergmann et al. This is an open access article distributed under the Creative Commons Attribution License, which permits unrestricted use, distribution, and reproduction in any medium, provided the original work is properly cited.

The acquisition and evaluation of acoustic emissions (AE) in tribology have proven to be a meaningful tool for condition monitoring and offer possibilities to deepen the understanding of tribological processes. The authors used this technology with the aim of expanding existing test methodologies towards increased visualization capability of tribological processes and investigated the correlation between tribological processes and acoustic emissions on a Ring-on-Disc and a close-to-component journal bearing test setting. The results of this study include the description of friction as well as wear processes and prove the usability of several $\mathrm{AE}$ evaluation parameters whereby a close correlation between $\mathrm{AE}$ and tribological processes can be shown. Consequently, it was possible to expand the visualization and evaluation capabilities of the test settings offering additional insights by making use of AE.

\section{Introduction}

Conventional tribological parameters such as coefficient of friction (COF), temperature, and contact resistance offer detailed information about ongoing tribological processes when applied on tribological test rigs. However, for industrial applications, their use is often connected with unjustifiable effort and insufficient results [1,2]. The acquisition of acoustic emissions (AE) represents a promising phenomenon if the acquisition itself can be conducted effectively. The subsequent analysis of emitted AE offers a wide range of possibilities to deepen the understanding of friction and wear processes.

$\mathrm{AE}$ are elastic waves generated by rapid release of energy [2]. Sources of $\mathrm{AE}$ are numerous and include deformation, fracture, or crack initiation and propagation, which made and still make the observation of AE a useful tool for machine and structure fault detection intended to enhance operation and to avoid unpredictable failures [3-6]. Subsequently, the evaluation of AE has been increasingly applied in tribological processes such as investigations of friction and wear processes as well as cavitation phenomena $[1,7,8]$. A comprehensive overview of the development of $\mathrm{AE}$ in condition monitoring of tribological systems is given by Mba and Rao [9]. Fields of interest include both conformal and nonconformal contacts on model scale as well as industrial application. Roller bearings as a representative of Hertzian contacts have been investigated by many authors $[7,8,10-15]$.

In terms of relative sliding motion, Lingard and $\mathrm{Ng}$ [16] conducted dry sliding tests on a two-disc wear machine and linked $\mathrm{AE}$ to frictional processes. The relationship between frictional work and threshold cumulative scalar was stated and it allowed the description of systematic investigations and variation of load, speed, and material.

The link between $\mathrm{AE}$ and wear was published by Boness et al. [17] in 1990. On a ball-on-cylinder test rig, dry and lubricated sliding tests were conducted including various material combinations. By calculating the root mean square of the acquired AE signal (AE RMS), a measurement was established which allowed the author to distinguish between wear under dry condition and wear under lubricated condition as well as investigate diverse wear mechanisms. The frequency content of emitted $\mathrm{AE}$ under variation of wear rates and wear and friction regimes of a sliding contact was investigated by Lingard et al. [18] in 1993. Hase et al. [7] performed sliding wear investigations on a pin-on-block test setting and linked stimulated frequencies of the AE signal to wear processes. By further literature revision, the authors composed an overview of the relation between occurring 
frequencies and correlating amplitudes and friction, respectively, wear processes. Actual investigations of AE generated in sliding motion deal with friction and wear investigations and the evaluation of acquired $\mathrm{AE}$ signals with mathematical tools $[19,20]$.

Early investigations regarding journal bearings focused on condition monitoring by Schwalbe [21]. Sturm and Uhlemann [22] investigated the state of lubrication of plain bearings with the help of $\mathrm{AE}$ and presented the possibility of detecting the transition from fluid to mixed lubrication regime by AE analysis. Similar tests were performed by the authors of [1]. By evaluating the AE RMS during a speed ramp, a typical behavior, according to Stribeck's findings [23], was observed allowing the identification of lubrication regimes by $\mathrm{AE}$ solely. The acquired time dependent $\mathrm{AE}$ signal was further transferred into the frequency domain. By plotting the resulting Fast Fourier Transformation of the signals chronologically, a water fall diagram was created. With the help of this evaluation, it was possible to detect starting seizure prior to conventional measurements like COF or temperature. The authors of [24] performed tests on various journal bearing test rigs and investigated the borders of $\mathrm{AE}$ measurement application. A correlation between $\mathrm{AE}$ and the frictional behavior in the fluid and mixed friction regime is presented in this study. Similar to [1], a more intense acoustic emission signal along with increasing speed was recorded which the authors linked to the increased number of collisions and intensity of impulses of fluid molecules resulting from the increased shear rate.The presented literature and further references [25-32] have successfully proven the use of $\mathrm{AE}$ analysis in tribological context providing deeper insights into and better understanding of tribological processes. In view of this, this study aims at using $\mathrm{AE}$ in establishing an additional tribological parameter. In addition to the already established measurement parameters such as $\mathrm{COF}$ and temperature, sound as an associated phenomenon of tribological processes should be made accessible to enlarge the visualization capability of tribological testing. Consequently, the main investigation subjects are emphasized as follows:

(a) Evaluation of the usability of $\mathrm{AE}$ analysis by investigating the correlation between friction and wear and measurement of $\mathrm{AE}$ events during sliding friction

(b) Evaluation and selection of suitable AE evaluation parameters

(c) Application of the AE evaluation methodology on two test settings and evaluation of its capability to visualize tribological processes

\section{Materials and Methods}

Tribological testing involved investigations with two test settings: a Ring-on-Disc (RoD) setting and a Journal Bearing Adapter (JBA) setting. Figure 1 visualizes the possible application fields of the two used test settings with the help of the Stribeck curve. While the RoD setting allows detailed investigations in the boundary and mixed friction regime of

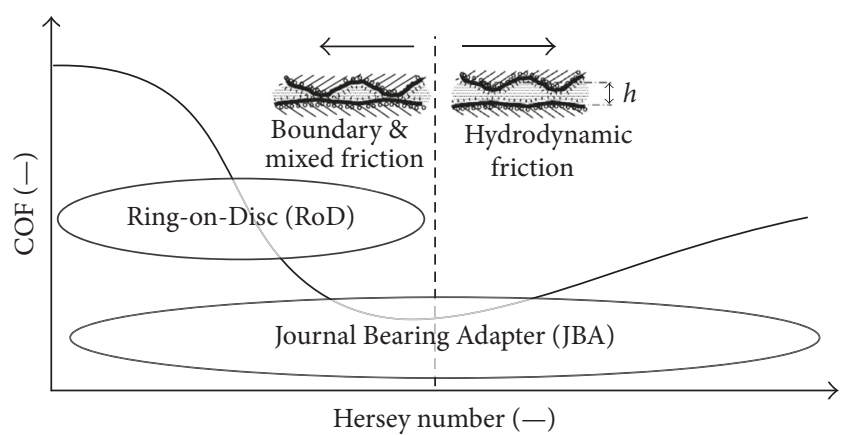

FIgURE 1: Possible operation regimes of the used test settings visualized with the help of a Stribeck curve. The Ring-on-Disc (RoD) setting allows investigations in the regime of boundary and mixed friction. The Journal Bearing Adapter (JBA) extends the possibilities to the fluid friction regime.

a typical journal bearing contact on reduced model scale, the JBA expands the areas of application to the fluid friction regime in a close-to-component contact. The investigation possibilities of the RoD setting incorporate friction as well as wear investigations on lubricants and interaction of materials [33-35]. The contact area and the loading forces are small in comparison to industrial applications. Consequently, the energy entry is low, which allows deceleration and detailrich investigation of friction and wear processes. This test setting is a suitable tool for developing methods and drawing principle conclusions, for which reason it was used for conducting basic investigations and evaluation of AE parameters. With the help of the JBA, close-to-component tests can be conducted, thereby allowing detailed friction and wear investigations of boundary, mixed, and fluid friction regime while still keeping a close link to the industrial application [34].

2.1. RoD Test Configuration. The RoD test setting was used in combination with a rotary tribometer TE92 from Phoenix Tribology (see Figure 2). The tribometer is mainly comprisesd of a driving unit delivering rotational speed and torque via the drive shaft (1) and the loading unit. The tribological contact is realized in a test cell. The oil bath (2) which contains the lubricant is pivot-mounted on the tribometer's cross head. Via heating elements, this bath and the tribological system can be heated. The cross head is guided by pillars to ensure an accurate vertical movement and is supported by air bellows which load the tribosystem with the normal force $F_{N}$. To avoid interaction with the surrounding atmosphere and contamination, the test cell is protected by a splash guard (3). The two specimens, ring and disc, fulfil a relative sliding motion within this pot and are fully oil-immersed. The ring specimen represents the crankshaft while the rotating disc specimen represents the multilayer buildup of a journal bearing. The temperature $T_{1}$ is measured on the cylinder jacket surface of the ring specimen yielding the system's temperature and is used for heat regulation. The contact close temperature $T_{2}$ is measured beneath the contact zone in the ring specimen. The frictional force resulting from the 


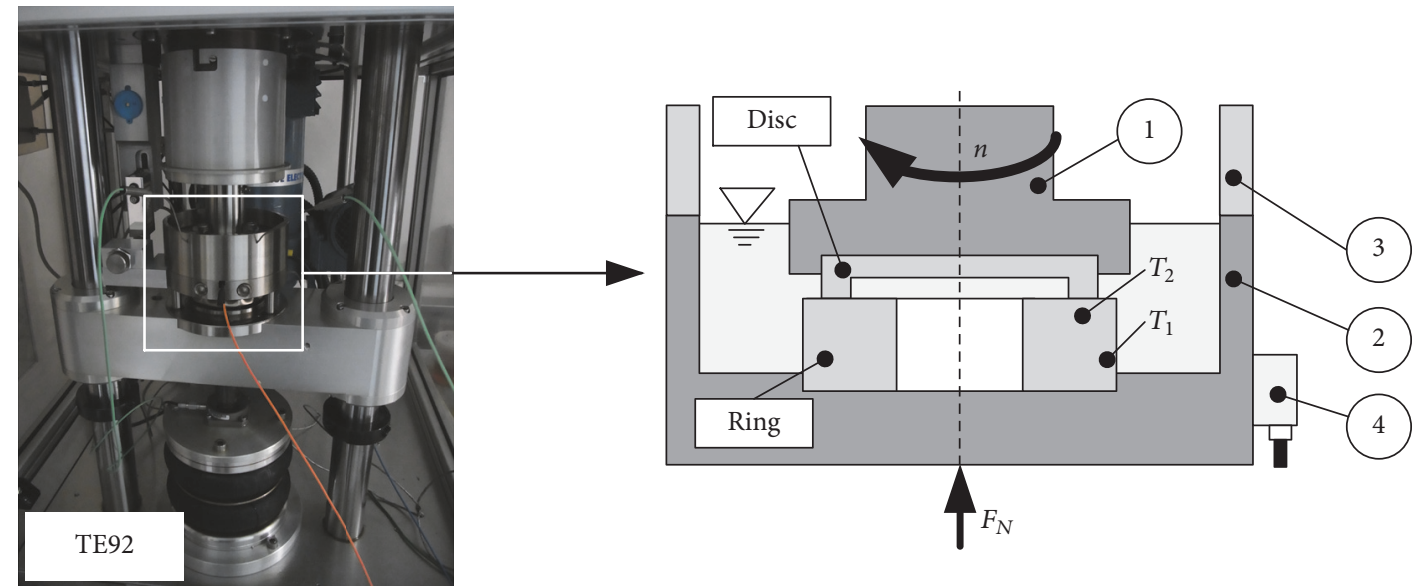

FIGURE 2: Ring-on-Disc (RoD) test setting and a schematic representation of the test cell. (1) Driving shaft, (2) oil bath, (3) splash guard, and (4) AE sensor.
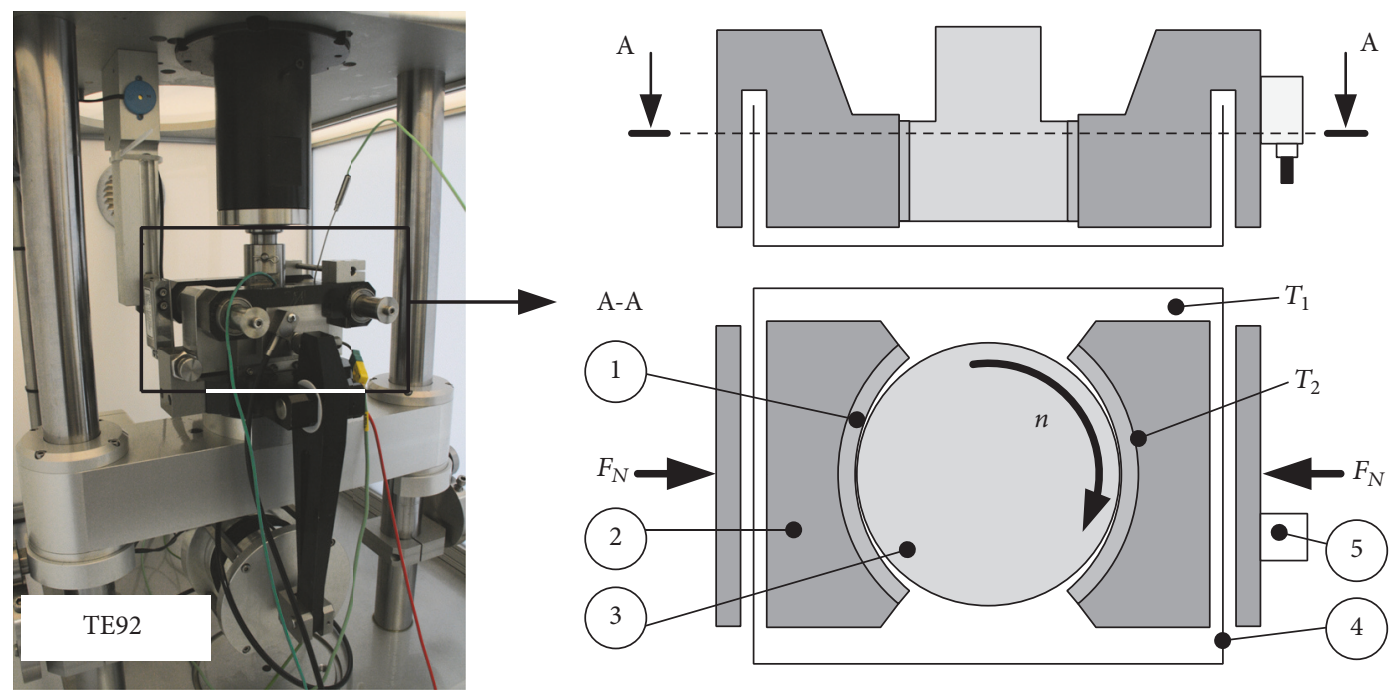

Figure 3: Journal Bearing Adapter (JBA) and a schematic representation of the test cell. (1) $120^{\circ}$ journal bearing shells, (2) specimen holder, (3) shaft specimen, (4) oil bath, and (5) AE sensor.

frictional processes in the contacting interface is measured by a lever mechanism and a load cell. The installed contact potential (CP) measurement enables the supervision of the state of friction. The $\mathrm{CP}$ is a contact resistance measurement and sheds light on the state of contact provided the specimens are conducting. A CP value of $0 \mathrm{mV}$ states direct contact of both specimens. A rising CP suggests increasing isolation between both surfaces by the formation of boundary layers, a lubrication film, or particles. This setup additionally provides a capacitive measurement of the wear height $h_{w}$. For actual purposes, the AE sensor (4) was applied on the pot allowing the recording of AE.

2.2. JBA Test Configuration. The JBA is pivot-mounted on the cross head of the rotary tribometer TE92 from Phoenix Tribology. The specific setup of the JBA can be found in [36]. The on-top mounted motor provides rotational speed and torque via the driving shaft as illustrated in Figure 3. The two 120-degree journal bearing shells (1) are mounted in the specimen holders (2) which are further connected to the adapter. A lever mechanism multiplies the force of the air bellow and pushes the two bearing shell specimens against the rotating shaft specimen (3) with an adjustable load $F_{N}$. The shaft specimen is mounted directly on the driving shaft. An oil bath (4) provides oil supply and can be heated. The COF is measured analogous to the RoD setting via a lever mechanism and taking advantage of the test cell's pivot mounting. A thermoelement measuring temperature $T_{1}$ is placed in the oil bath and also used for regulation purposes. A second temperature $T_{2}$ is measured via a bore in the specimen holder revealing the contact close temperature at the back of one journal bearing specimen. The installed measurement of the CP yields information about the state of friction. In this case, not only processes mentioned above but also the 
TABLE 1: Used test components.

\begin{tabular}{lcc}
\hline Test setting & Test component & Description \\
\hline \multirow{3}{*}{ RoD } & Ring & 34CrNiMo6 \\
& Disc & Al-Sn sliding material \\
& Lubricant & FVA 3 \\
\hline \multirow{3}{*}{ JBA } & Shaft & 34CrNiMo6 \\
& Journal bearing & Al-Sn sliding material \\
& Lubricant & Shell Rimula 10 W \\
\hline
\end{tabular}

formation of a load carrying hydrodynamic fluid film leading to complete separation of both surfaces can be observed. This setup does not provide an in situ wear observation of why either a thickness or mass loss measurement is required. The $\mathrm{AE}$ sensor (5) was placed on the back of one specimen holder to acquire the AE.

2.3. Test Parameters. Investigations on the RoD setting were performed with the use of FVA 3 base oil as a lubricant. The disc specimen had the multilayer structure of a journal bearing and was composed of a steel disc coated with an aluminium based sliding material. The material of the ring specimen was typical crankshaft steel. The involved parts in the conducted tests of the JBA were chosen to be comparable with the RoD setting but represented components from industrial application. The used lubricant was Shell Rimula $10 \mathrm{~W}$. For the shaft specimen, the same typical crankshaft steel was used as in the RoD setting. The journal bearing specimens consisted of a steel back and aluminium based sliding material on a bronze lining layer. Table 1 summarizes the used components for both test settings.

2.4. Test Strategies. Conducted tests involved seizure load limit tests by making use of the RoD test setting. Temperature load tests were conducted with the JBA. Both test strategies aimed at pushing a stable operating system into unstable conditions accompanied by wear.

2.4.1. RoD-Seizure Load Limit Test. A seizure load limit test aims at working out the load limit of the tribological material combination by incrementally increasing the normal load until the system is pushed to its limit where seizure and failure occur. For further information about this type of test, see [37] or [38]. The input parameters as a function of time are shown in Figure 4. The sliding speed is kept constant throughout the entire test period at $1.4 \mathrm{~m} / \mathrm{s}$. External heating is disabled. Changes in the measured temperature originate solely from dissipated heat of the tribological contact. During the initial running-in phase, the load is set to $3 \mathrm{MPa}$ for $4200 \mathrm{~s}$. In the subsequent loading phase, the load is increased by $1 \mathrm{MPa}$ every $1200 \mathrm{~s}$ via a ramp of $300 \mathrm{~s}$. The tests are stopped at certain stages of wear which are identified with the help of the measurement variables.

2.4.2. JBA-Temperature Load Test. The input quantities as a function of time are depicted in Figure 5. The initial conditions are set to a sliding speed of $0.4 \mathrm{~m} / \mathrm{s}$ and a normal

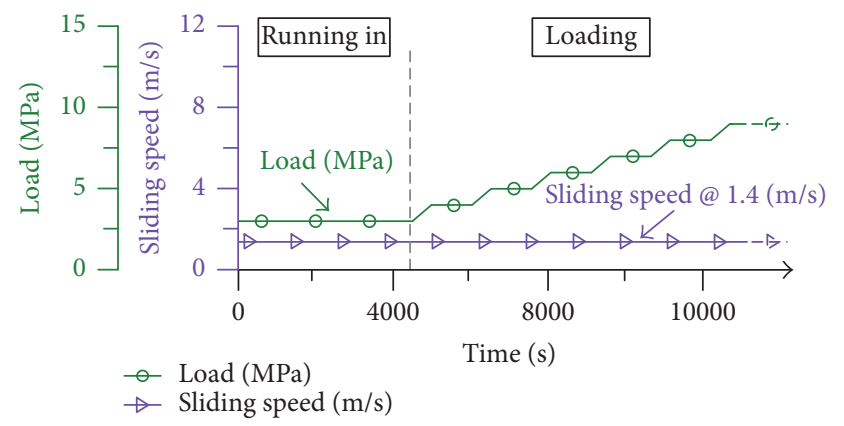

FIGURE 4: Input parameters of the seizure load limit test performed with the RoD test setting.

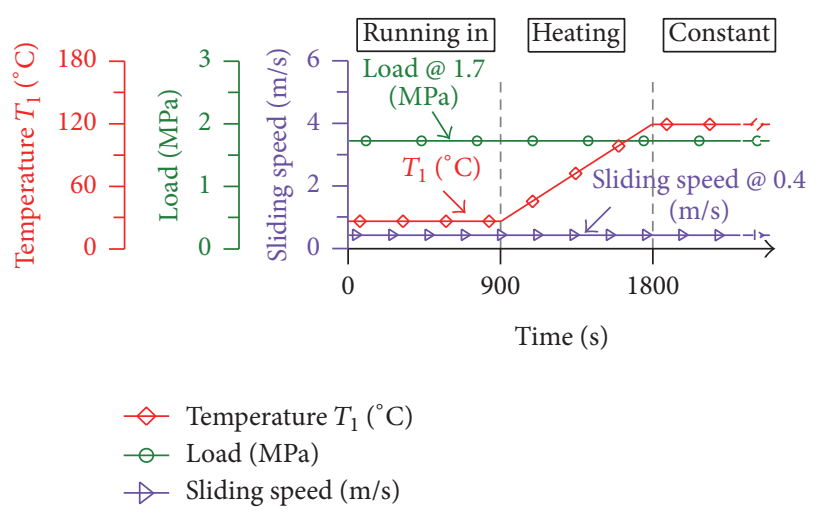

FIGURE 5: Input parameters of the temperature load test performed with the JBA test setting.

load of 1.7 MPa while keeping the external heating disabled. After the running-in phase which lasts for $900 \mathrm{~s}$, external heating is enabled. The system's temperature is raised from room temperature to $120^{\circ} \mathrm{C}$ within $900 \mathrm{~s}$ while keeping speed and external load at a constant level. During the constant phase, the external input parameters remain constant. The test sequence is stopped at certain stages of wear.

2.5. AE Signal Evaluation. Structure-borne noise was recorded via a piezoelectric acoustic emission sensor Piezotron ${ }^{\circledR}$ Sensor Type $8152 B$ from Kistler with a maximum operating temperature of $60^{\circ} \mathrm{C}$, respectively, the equivalent type $8152 \mathrm{C}$ which allows investigations up to $165^{\circ} \mathrm{C}$. These types of sensors are suitable for measuring frequencies above $50 \mathrm{kHz}$. The maximum sensitivity of $57 \mathrm{~dB} \cdot \mathrm{V} /(\mathrm{m} / \mathrm{s})$ ranges from $50 \mathrm{kHz}$ to $400 \mathrm{kHz}$. Between $400 \mathrm{KHz}$ and $1000 \mathrm{kHz}$, the sensitivity decreases linearly to a value of $23 \mathrm{~dB} \cdot \mathrm{V} /(\mathrm{m} / \mathrm{s})$. The time dependent output voltage of the AE sensor was further transferred to a Kistler Piezotron Coupler Type 5125B (see Figure 6). The amplifier gain of the coupler was $40 \mathrm{~dB}$ and the signal was filtered by means of a Butterworth band pass filter between $50 \mathrm{kHz}$ and $1000 \mathrm{kHz}$. The specified output noise level of the resulting signal is below $10 \mathrm{mV}$. The filtered signal was further transmitted to an analog/digital converter, National Instruments type NI USB-6361. The sampling frequency was chosen as $2 \mathrm{MHz}$ in order to fulfil the Nyquist-Shannon sampling theorem. After digitalization, 


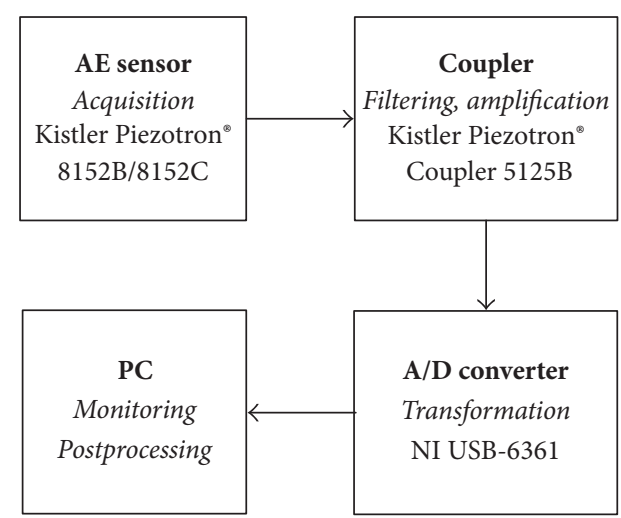

FIgUre 6: Acoustic emission (AE) evaluation chain.

transmission via a USB port to the PC was carried out. The provided data was used for in situ condition monitoring and was additionally postprocessed. Measurements of 36000 data points were conducted at specified time intervals to ensure a practical amount of data. Since the specified noise level of the output signal is less than $10 \mathrm{mV}$, only values above this threshold were taken into consideration for the subsequent evaluation.

For evaluation purposes, the reviewed literature reveals numerous approaches of signal analysis of which the parameters described below were chosen by rating the mathematical effort and its informative value. Of regard was in particular the capability to characterize tribological processes on the one hand and the evaluation power of the accumulated parameter on the other hand.

2.5.1. AE Root Mean Square (AE RMS) [V]. The use of the $A E R M S$ has already been presented by several authors, who concluded the practicable and valuable results originating by using this parameter $[8,27-32]$. In an additional step, the $A E$ $R M S$ of the acoustic emission signal is accumulated by taking the integral over time resulting in the value accumulated $A E$ $R M S$. The subsequently described parameters were accumulated in an analog matter.

2.5.2. Count Rate $\dot{N}[1 / s]$. The count rate $\dot{N}$ specifies the number of exceedances of the noise threshold $(10 \mathrm{mV})$ during the period of measurement.

2.5.3. Parameter $p[V]$. The idea of the calculation of this parameter is based on the work of Baranov et al. [2]. By analyzing the composition of the acquired time dependent signal, the distribution of amplitudes $A_{j}$ and their corresponding number of pulses $N_{j}$ can be revealed. The product of these two values leads to the parameter

$$
p=N_{j} \cdot A_{j}
$$

2.5.4. AE Energy $\left[V^{2} s\right]$. The acoustic emission energy $E_{\mathrm{AE}}$ is the integral of the squared output voltage amplitude $V(t)$ over the duration of measurement $(t)$ which can be expressed by [39]

$$
E_{\mathrm{AE}}=\int_{0}^{t}[V(t)]^{2} d t
$$

2.5.5. Standard Deviation of the Amplitude, $\sigma$ [V]. This parameter is obtained by analyzing the probability density function of the time dependent signal. Baranov et al. [2] showed that this characteristic changes during running-in processes depending on the state of operation and hence serves as an evaluation parameter of tribological processes.

\section{Results and Discussion}

The following section presents and discusses the achieved tribological and the corresponding $\mathrm{AE}$ results. Possible $\mathrm{AE}$ evaluation parameters are presented. As a key factor, the reproducibility of tribological results in interplay with $\mathrm{AE}$ results is investigated followed by the presentation of the $\mathrm{AE}$ wear correlation and surface analysis.

3.1. Tribological Test Results: RoD. The tribological results of an exemplary test (Test A) conducted with the RoD settings are depicted in Figure 7(a) including the resulting measured quantities of the presented seizure load limit test program: the dimensionless coefficient of friction (COF), the contact potential (CP) in $\mathrm{mV}$, the system temperature $T_{1}$ and contact close temperature $T_{2}$ in ${ }^{\circ} \mathrm{C}$, and the capacitive measured wear height $h_{w}$ in $\mu \mathrm{m}$. For the creation of the subsequent $\mathrm{AE}$ wear dependence, further tests, which are shown in Figure 8, were conducted and stopped at different stages of wear progress. During the running-in phase (0s-4200s), all input parameters are kept constant. The operation in a state of mild mixed friction leads to advancing mutual surface adaption. These running-in processes lead to an energy optimized state of contact consequently resulting in a continuously decreasing COF. The CP rises within the first seconds to its maximum value of $50 \mathrm{mV}$ and fluctuates at this level. Until the CP drops at $800 \mathrm{~s}$, the system remains stable, indicated by a high CP value and a steadily decreasing COF due to running-in processes. The CP's drop occurs in connection with an increase of the COF which suggests local adhesive bonding events. After that, the system recovers and remains in stable mixed friction regime accompanied by running-in processes indicated by the steadily decreasing COF. With the onset of the stepwise increasing load, the COF decreases at each consecutive load step. The reason for this is a change in the real area of contact. While the real contact area does not increase proportionally to the external load during the first 4 load steps, a constant share between real contact area and external load is reached from this time on resulting in a constant COF. During the first load ramp, the $\mathrm{CP}$ shows a slight drop. This phenomenon continues with consecutive load steps but shows a more intense occurrence with advancing load. The temperature also increases at each load ramp and remains at a constant level during the constant loading phase. At the load of $7 \mathrm{MPa}$, the CP starts to sink continuously. Along goes a change in the inclination of the 


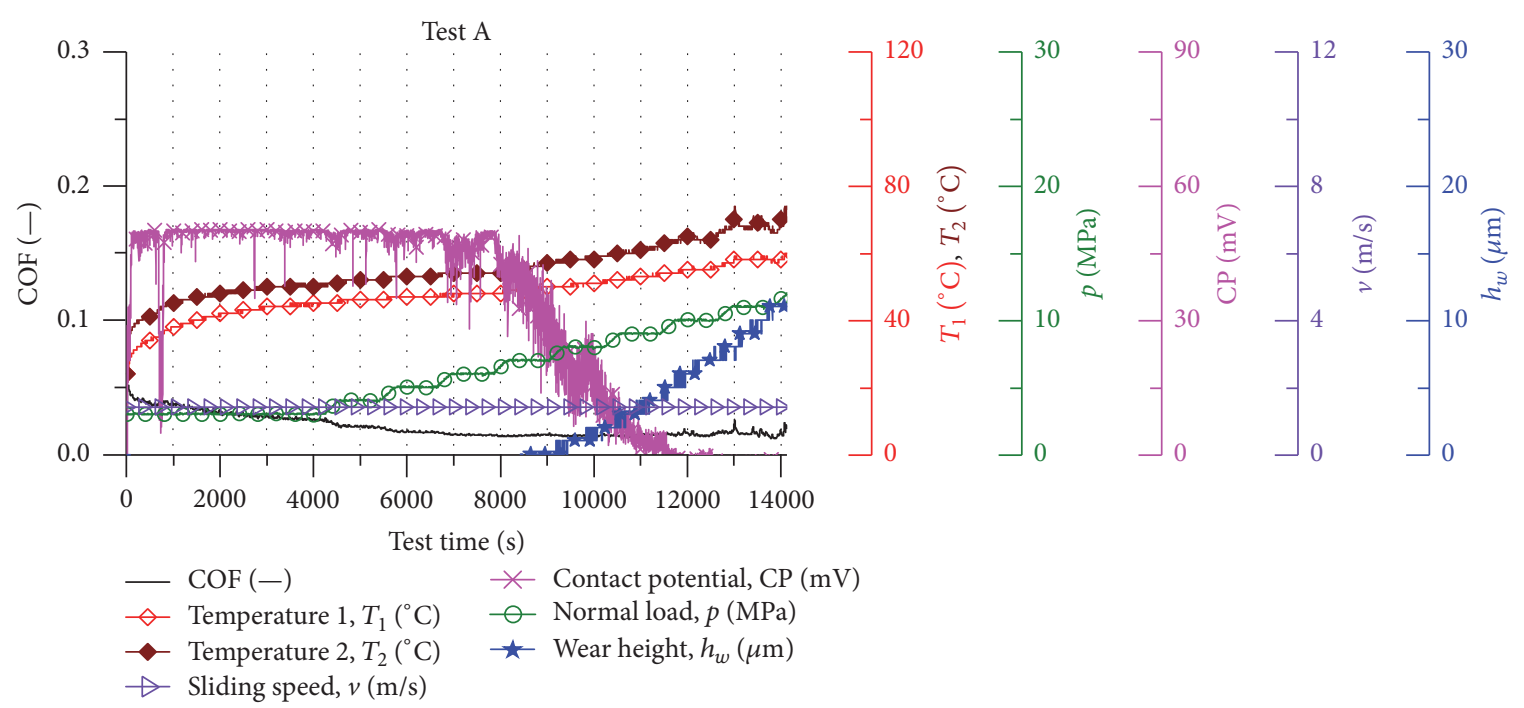

(a)

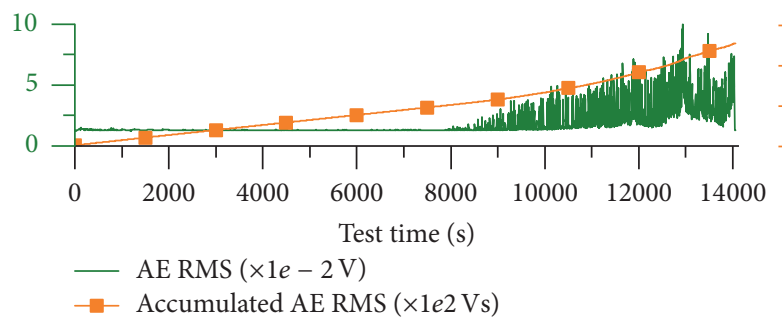

(b)

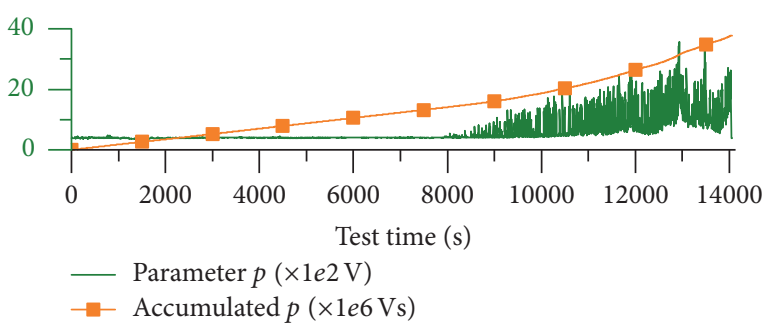

(d)

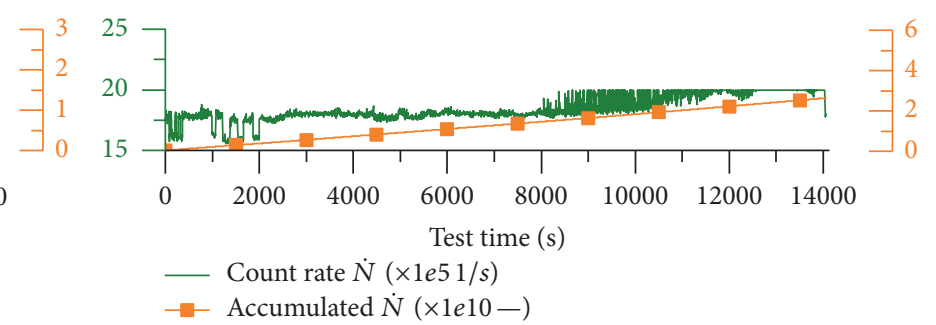

(c)

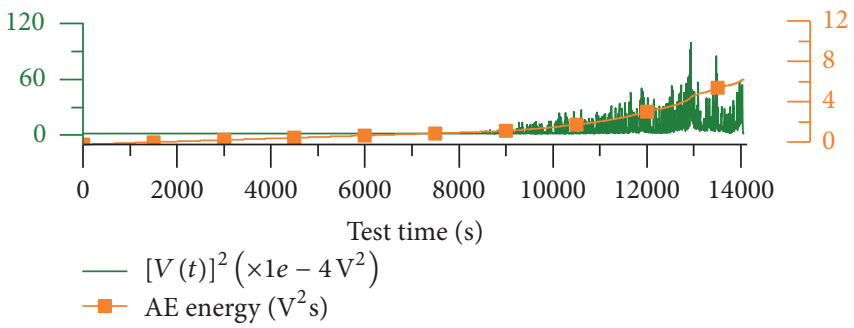

(e)

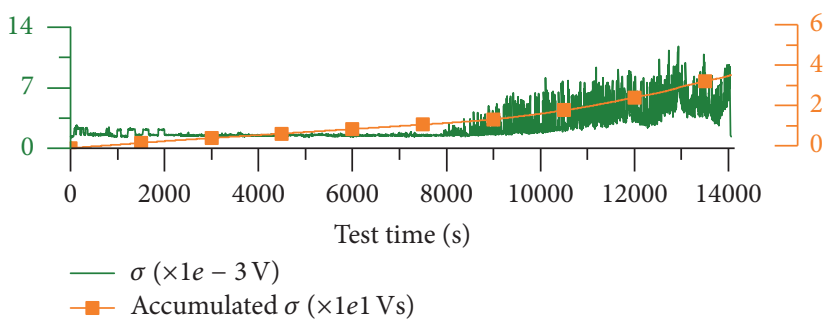

(f)

FIGURE 7: Tribological and correlating AE results of a representative load limit test conducted with the RoD setting.

temperature from a degressive to progressive run. The ramp to a load of $8 \mathrm{MPa}$ indicates the onset of wear, illustrated by the increasing wear height. Since temperature and COF show a steady behavior, the system operates in a constant wear regime. At approximately $12000 \mathrm{~s}$, the CP completely drops to 0 while the COF and especially the contact close temperature $T_{2}$ show a more hectic behavior. The test is stopped when $T_{1}$ reaches the set maximum temperature of $60^{\circ} \mathrm{C}$ after $14000 \mathrm{~s}$. The final volume loss of the disc specimen sums up to $1.89 \mathrm{~mm}^{3}$. Figures 7(b)-7(f) depict the calculated AE parameters. Considering the run of AE RMS in Figure 7(b) representatively, it can be seen that the parameters show an increased activity as well as an elevated level during phases of low CP which are linked to running in (0s-2000s), 

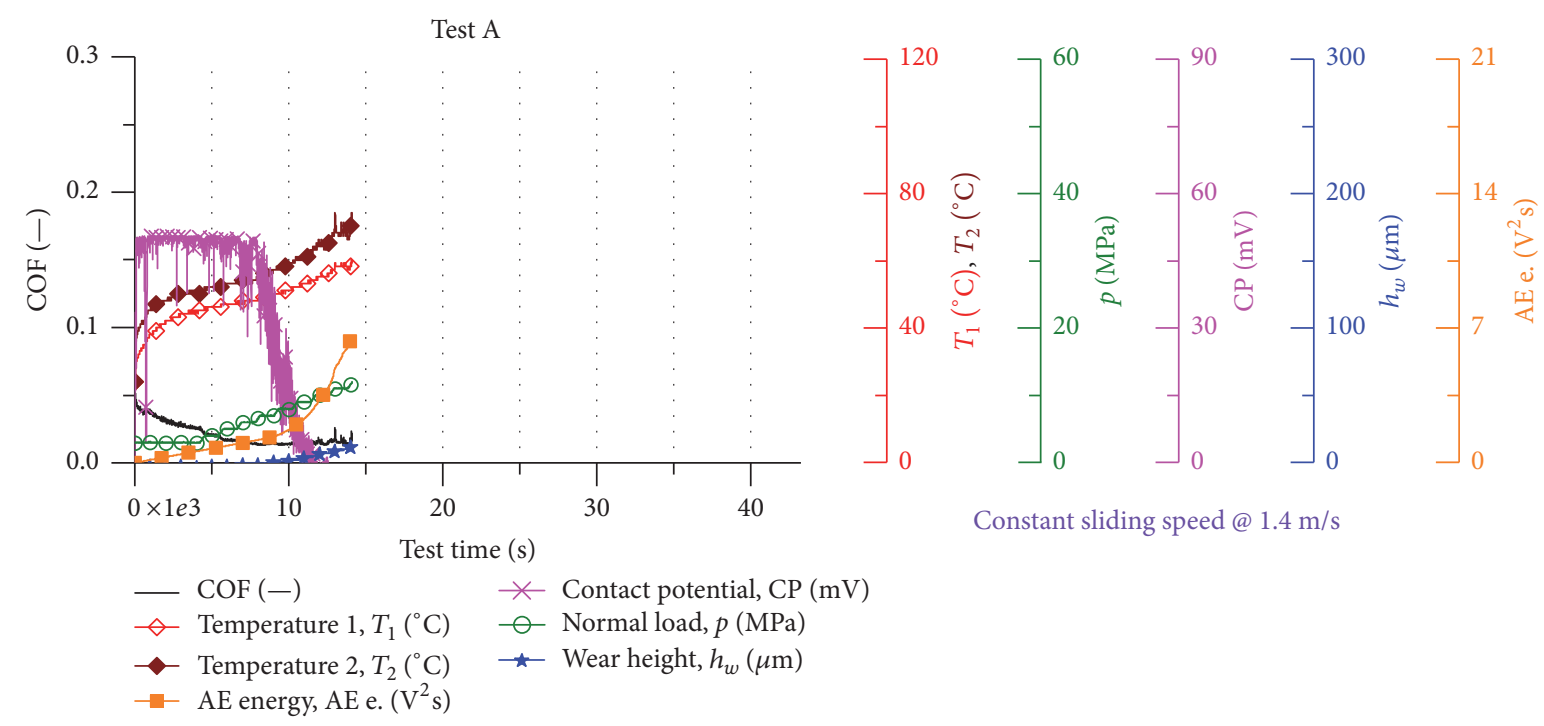

Constant sliding speed @ $1.4 \mathrm{~m} / \mathrm{s}$
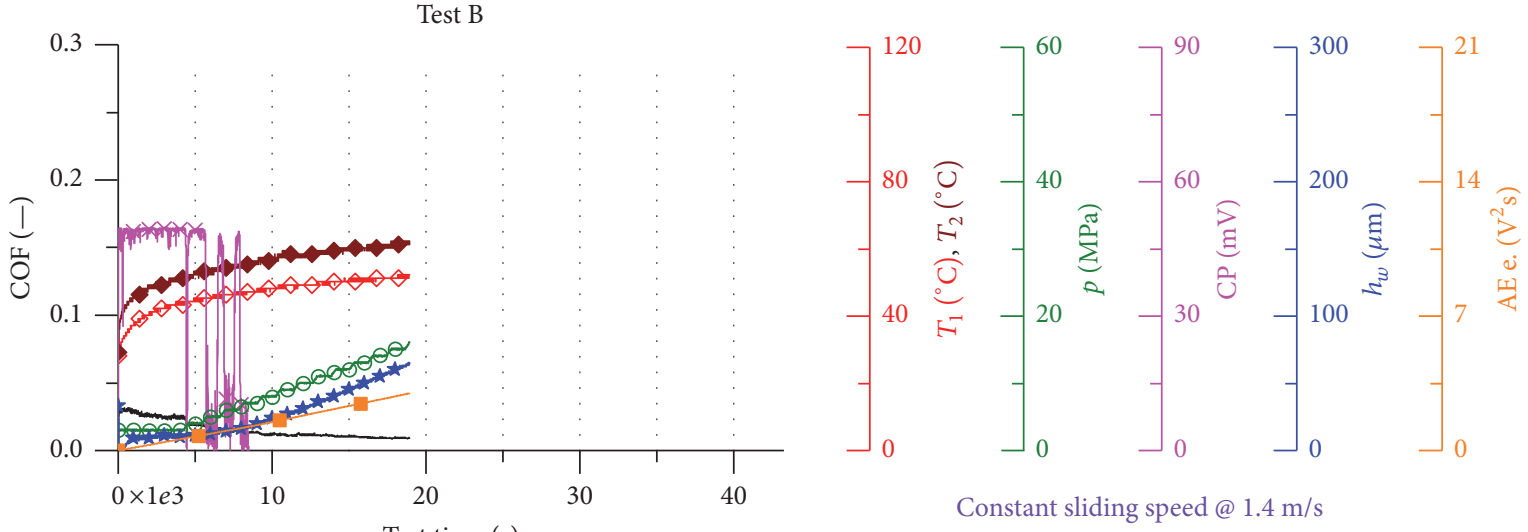

Test time (s)

Constant sliding speed @ $1.4 \mathrm{~m} / \mathrm{s}$

$-\mathrm{COF}(-) \quad \times$ Contact potential, $\mathrm{CP}(\mathrm{mV})$

$\diamond$ Temperature $1, T_{1}\left({ }^{\circ} \mathrm{C}\right) \quad \smile$ Normal load, $p(\mathrm{MPa})$

$\neg$ Temperature $2, T_{2}\left({ }^{\circ} \mathrm{C}\right) \quad \star$ Wear height, $h_{w}(\mu \mathrm{m})$

$-\mathrm{AE}$ energy, $\mathrm{AE}$ e. $\left(\mathrm{V}^{2} \mathrm{~s}\right)$
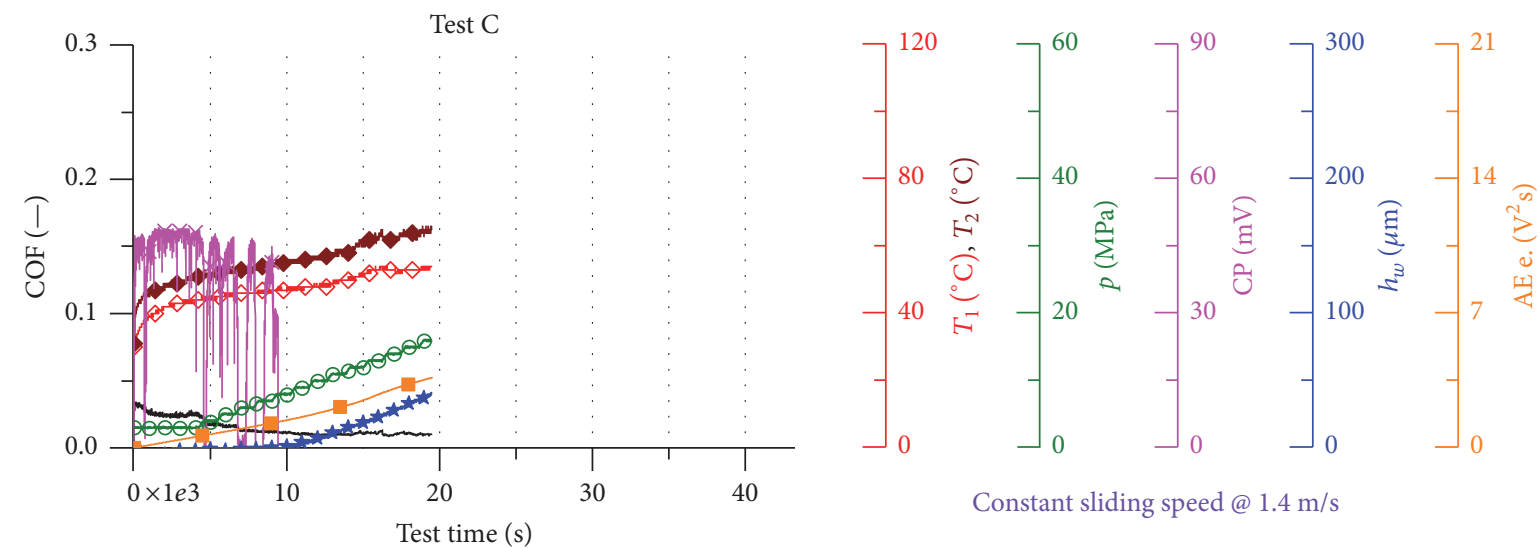

Constant sliding speed @ $1.4 \mathrm{~m} / \mathrm{s}$

\footnotetext{
COF $(-)$

$\star$ Contact potential, $\mathrm{CP}(\mathrm{mV})$

$\diamond$ Temperature $1, T_{1}\left({ }^{\circ} \mathrm{C}\right) \quad \bigcirc$ Normal load, $p(\mathrm{MPa})$

$\downarrow$ Temperature $2, T_{2}\left({ }^{\circ} \mathrm{C}\right) \quad$ * Wear height, $h_{w}(\mu \mathrm{m})$

- $\mathrm{AE}$ energy, $\mathrm{AE}$ e. $\left(\mathrm{V}^{2} \mathrm{~s}\right)$
}

FIgure 8: Continued. 

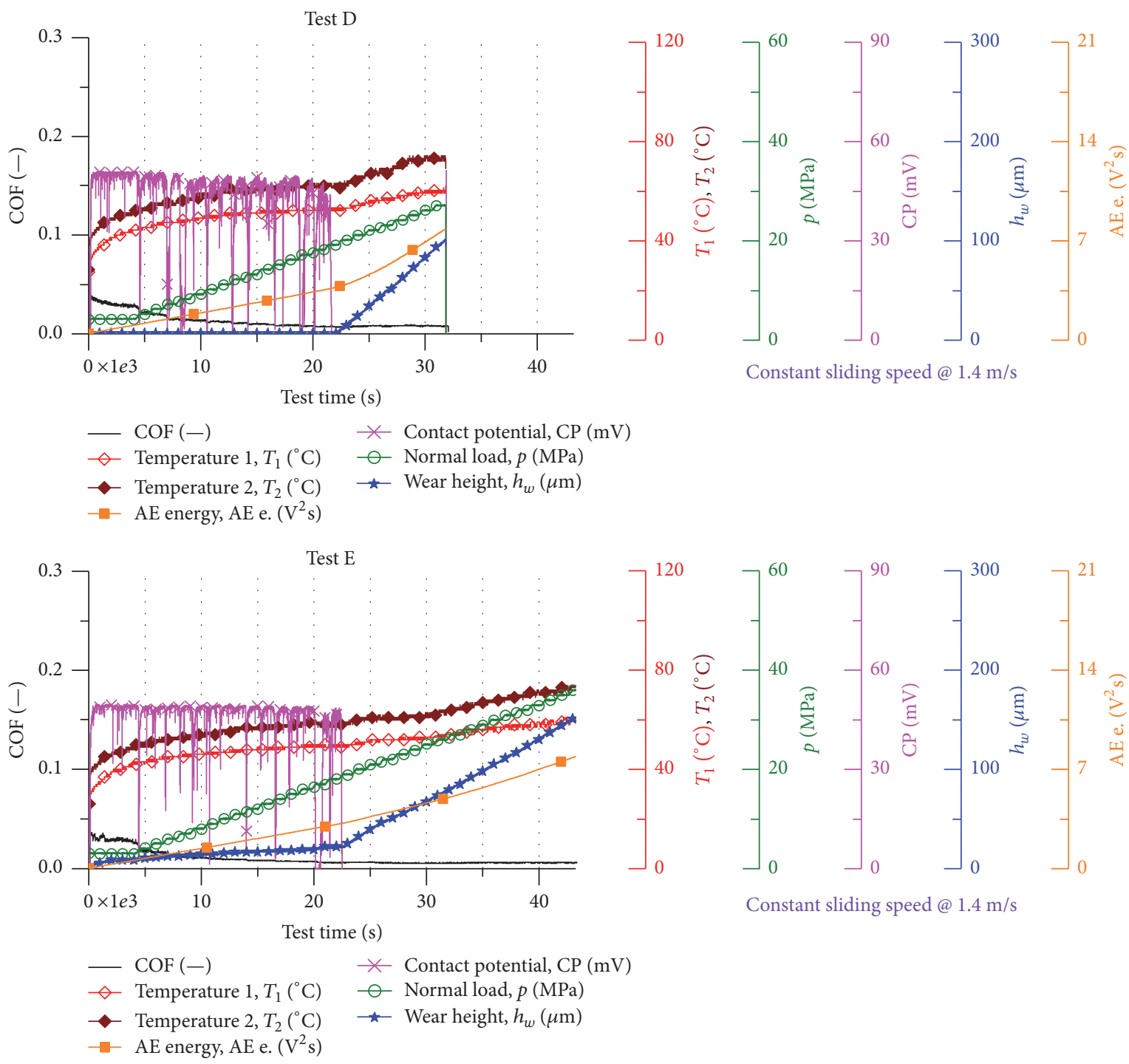

Constant sliding speed @ $1.4 \mathrm{~m} / \mathrm{s}$
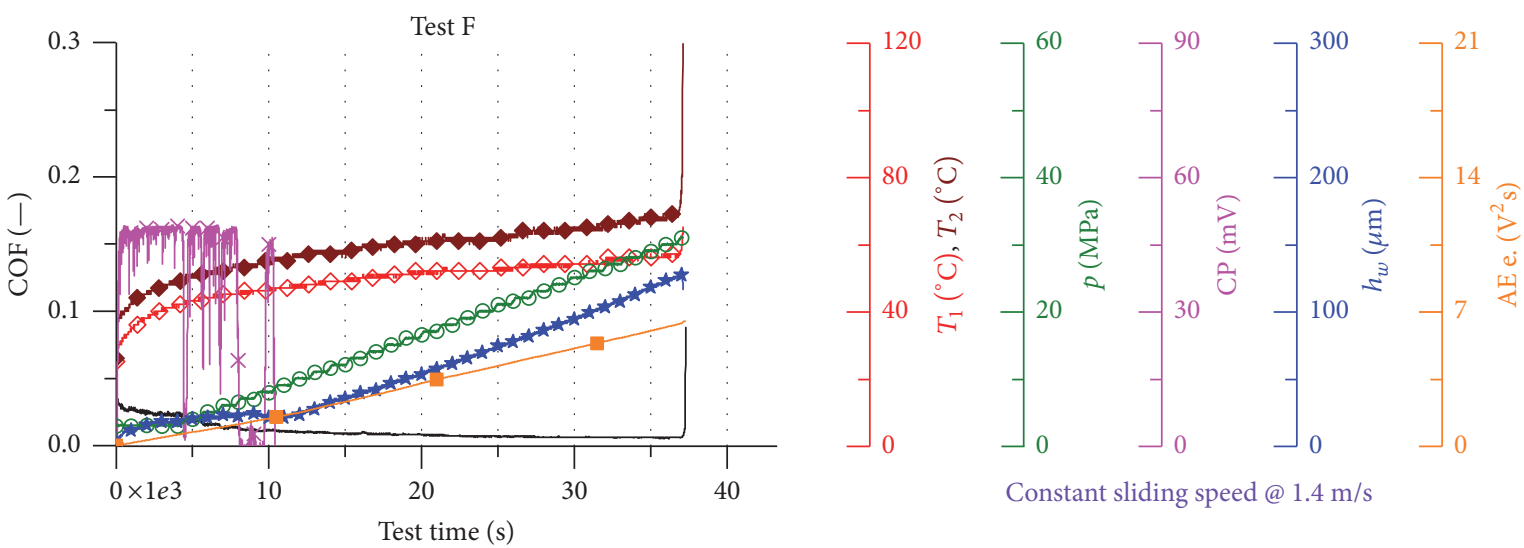

Test time (s)

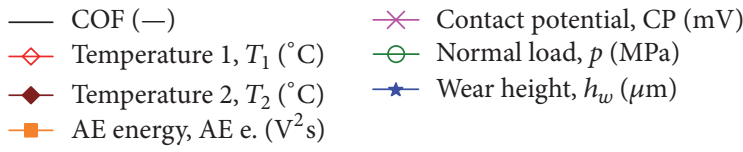

FIgURE 8: Tribological and AE test results of load limit tests A-F conducted with the RoD setting. 


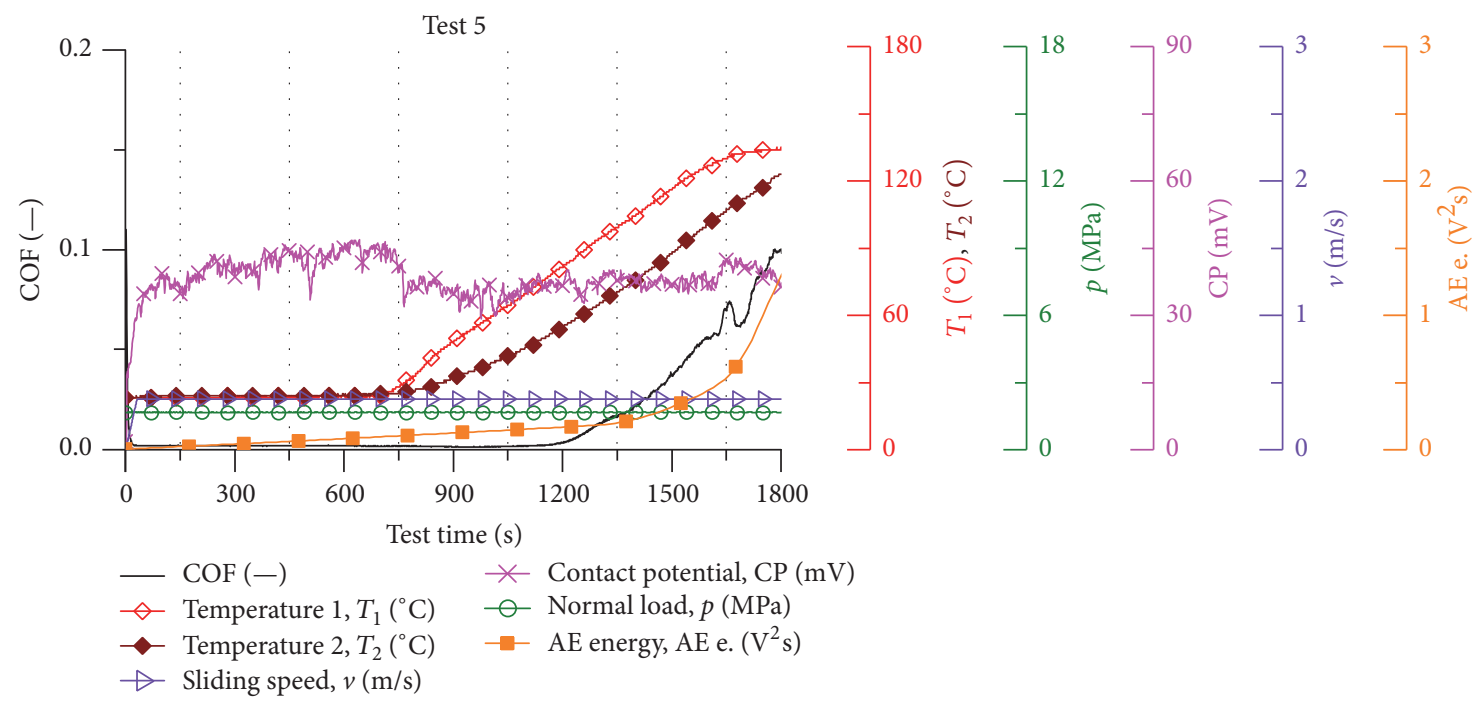

FIGURE 9: Tribological and correlating AE results of a representative temperature load test conducted with the JBA setting.

respectively, wear processes (9000 s-test end). During the time period between $2000 \mathrm{~s}$ and $8000 \mathrm{~s}$, which is governed by stable operation conditions, the AE RMS remains constant. Simultaneously, with the onset of an increasing wear height around $8000 \mathrm{~s}$, also the AE RMS starts to rise and behave hectically. The run of AE RMS from 130000 s on depicts a close correlation to the COF as can be seen at the coincident peaks of COF and AE RMS.

Within the initial $8000 \mathrm{~s}$, the accumulated AE RMS shows a linear run. Since the accumulated value represents the time integral of the AE RMS, this is the mathematical consequence of the integration of a constant value. This behavior turns into a nonlinear run with the onset of wear and an increased activity and elevated AE RMS values.

The count rate $\dot{N}$ in Figure 7(c) shows a reasonably constant run during the time range from $0 \mathrm{~s}$ to $8000 \mathrm{~s}$ despite the break-ins within the initial period of time. With the onset of wear, the count rate increases. This finding follows the described relation in [2], which links an increase of the count rate by $20 \%$ with the beginning of surface damage. The count rate reaches its maximum possible value of $2 e 6$ overshoots of $10 \mathrm{mV}$ during the period of high COF values around $13000 \mathrm{~s}$. Whereas the other parameters indicate the highest intensity during this period and are capable of visualizing graduation in the signal's intensity, the informative value of the count rate is limited during this time period. This can be influenced by changing the value of the threshold but ultimately leads to the drawback of the necessity of threshold adjustment. The accumulated count rate shows a linear run throughout the whole test period. In comparison to other accumulated evaluation parameters, the onset of wear by a change in inclination is not recognizable. The count rate is easy to implement and is a time efficient possibility for evaluation purposes but exhibits major drawbacks in comparison to the other parameters. The parameters $p, \mathrm{AE}$ energy, and $\sigma$ show a similar resolution and visualization capability compared to AE RMS, whereby the AE energy was chosen for further evaluation purposes since it represents a widely established parameter, which can also be used for comparative experiments [6].

3.2. Tribological Test Results: JBA. A representative temperature load test (Test 5) is depicted in Figure 9. The test data of further conducted tests are shown in Figure 10. During the initial $40 \mathrm{~s}$, a starting procedure of the tribological system can be observed. The high COF resulting from solid contact drops with increasing rotational speed following the behavior of a Stribeck curve. Consistently, the CP rises indicating increased resistance due to the formation of a hydrodynamic fluid film which in part separates the specimens' surfaces. The CP resides below the maximum of $50 \mathrm{mV}$ indicating an operation in the mixed friction regime. With advancing test time, surface asperities are worn out leading to an ascending run of the $\mathrm{CP}$ tending towards its maximum of $50 \mathrm{mV}$. The temperature remains constant indicating the absence of heat generating intense friction or wear processes. With the onset of external heating, an increase of the contact close temperature along with a decrease of the CP can be observed illustrating the film height reducing effect of decreased viscosity due to an elevated temperature. The drop of the CP signals a fallback into a more intense mixed friction state in which the system remains for the residual test period. Apart from that, measurands indicate stable conditions with continuing increasing temperature. At $1100 \mathrm{~s}$, the increasing temperature sufficiently reduced the load carrying capacity of the fluid film. Consequently, surface asperities interact more intensely resulting in higher frictional losses. The CP remains on a constant level and shows no influence of wear onset. As can be seen, the sensitivity of the $\mathrm{CP}$ with respect to wear processes is limited in this case. In contrast to the flat contact of the RoD setting, the permanently reforming and changing converging fluid film gap restricts the informative content 

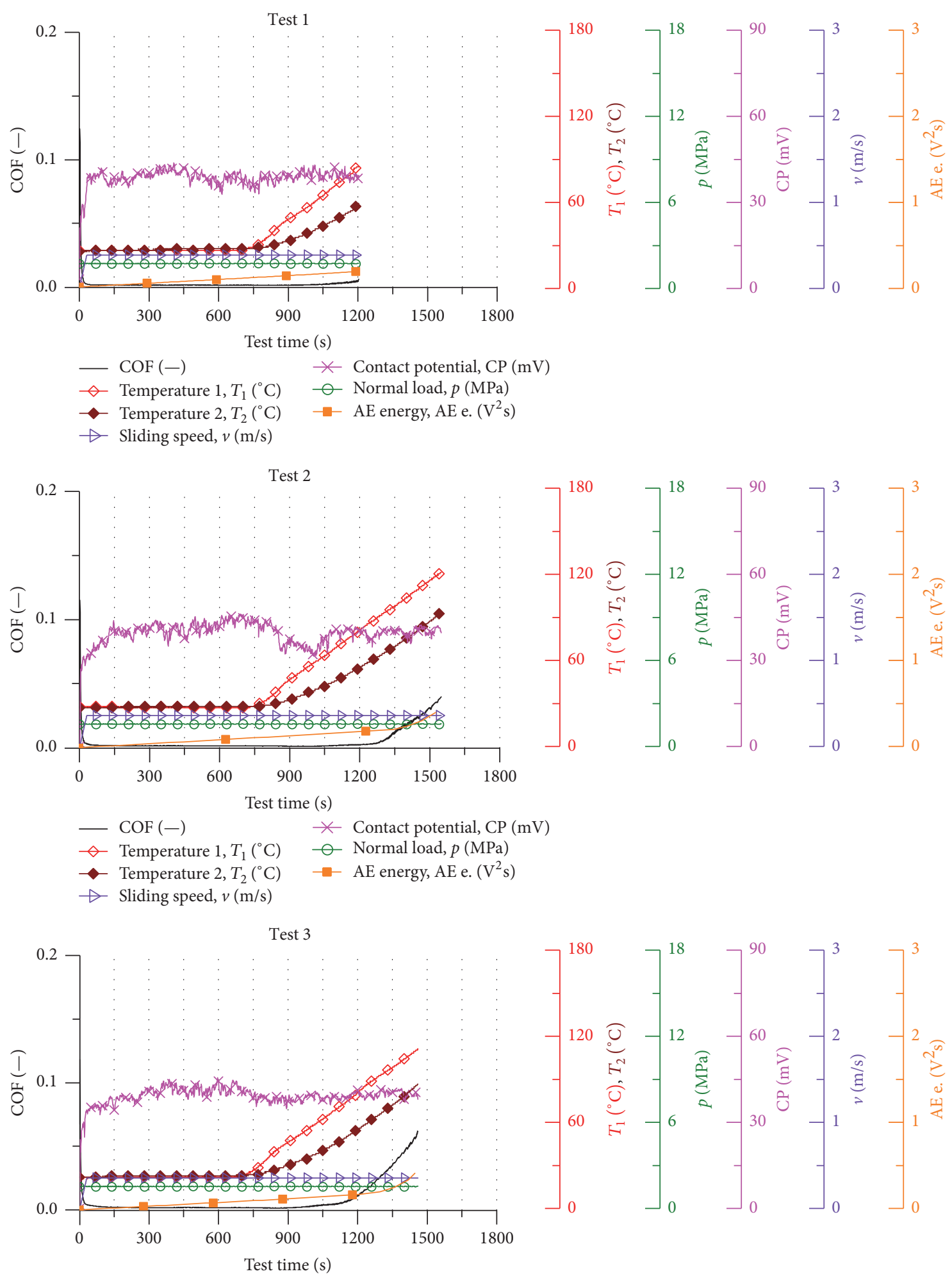

\footnotetext{
$-\mathrm{COF}(-) \quad \times$ Contact potential, $\mathrm{CP}(\mathrm{mV})$

$\diamond$ Temperature $1, T_{1}\left({ }^{\circ} \mathrm{C}\right) \quad \smile$ Normal load, $p(\mathrm{MPa})$

$\multimap$ Temperature $2, T_{2}\left({ }^{\circ} \mathrm{C}\right) \rightarrow \mathrm{AE}$ energy, AE e. $\left(\mathrm{V}^{2} \mathrm{~s}\right)$

$\triangleright$ Sliding speed, $v(\mathrm{~m} / \mathrm{s})$
}

FIGURE 10: Continued. 

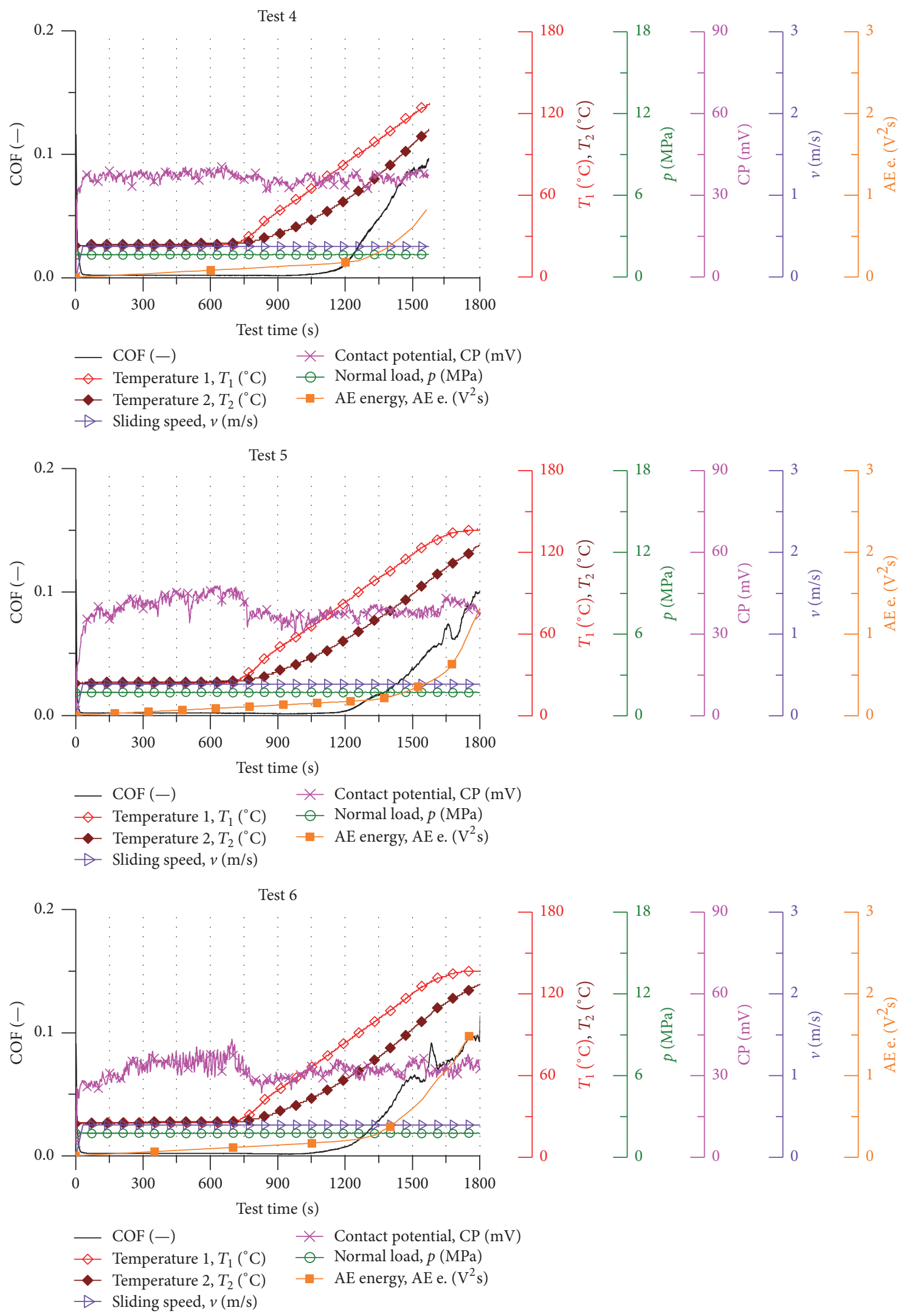

FIgURE 10: Tribological and AE test results of temperature load tests 1-6 conducted with the JBA setting. 
of the $\mathrm{CP}$ with respect to wear processes. The continuously rising temperature leads to a reduction of the hydrodynamic load carrying capacity. Consequently, the external load is increasingly carried by asperity contact, leading to an increased asperity interaction followed by a steady increase of the COF. The AE energy shows a linear increase until $1300 \mathrm{~s}$. Thereafter, the behavior turns into nonlinear and by analogy with the previously described test this change in inclination can be linked to the onset of wear. At the end of the test, the wear volume amounts to $12.83 \mathrm{~mm}^{3}$ whereas the AE energy sums up to $1.32 \mathrm{~V}^{2} \mathrm{~s}$.

\subsection{Reproducibility of Testing and AE Evaluation. A key} factor, which determines the suitability of a measurement method significantly, is the reproducibility of measurement data. For the evaluation of this aspect, the acquired tribometric and $\mathrm{AE}$ data of the 6 presented tests of each respective test setting during the stable initial phase are considered. This phase was run through by all tests and represents operation in stable conditions which allows a time dependent evaluation of the reproducibility of the tribological as well as the $\mathrm{AE}$ measurement quantities. Aside from these stable operation conditions, the results spread when it comes to wear in absolute numbers but still show high phenomenological reproducibility. The onset and progress of wear are closely linked to statistical influences regarding local contact conditions and an intrinsic scatter in material compositions. Furthermore, the occurrence of tribological and sliding events restricts the significance of the comparison of time periods which are accompanied by wear. For the evaluation of the tribological reproducibility, the $\mathrm{COF}$ as a decisive parameter is chosen whereas the $\mathrm{AE}$ energy is considered for the evaluation in the case of AE. Figure 11 depicts the maximum, minimum, and calculated mean run of the $\mathrm{COF}$, respectively, the $\mathrm{AE}$ energy of the 6 provided tests for each test setting during the initial $1200 \mathrm{~s}$ (JBA), respectively, $12000 \mathrm{~s}$ (RoD). However, the common stable operations are the initial $900 \mathrm{~s}$ in the case of the JBA setting and $10000 \mathrm{~s}$ in the case of the RoD setting. The runs of the COF of the conducted JBA tests in Figure 11(a) show a small scatter band between $150 \mathrm{~s}$ and 900 s. During this phase, the maximum relative deviation between the borders of the scattering range and the mean value is $31.1 \%$. However, the deviation during this period is close to the resolution power of the test rig. A comparable situation presents the COF run of the RoD tests, Figure 11(b). Analogously, the beginning is accompanied with running-in wear processes leading to a higher spread. In the later state of stable operation, the scattering range reduces leading to a maximum deviation of $32.3 \%$. Consequently, the presented details and the attached test plots show satisfying tribological reproducibility in terms of absolute numbers during stable conditions and phenomenological behavior in the presence of wear processes.

The corresponding AE results are depicted in Figures 11(c) and 11(d). In both cases, the plots show a narrow scattering band with a maximum relative deviation of the measured data from the mean value of $12.3 \%$ in the case of the JBA setting (c) and $15.1 \%$ in the case of the RoD setting (d) during the phase without wear. This presents high tribological test reproducibility during stable conditions on the one hand and attests a high level of robustness and reproducibility of the $\mathrm{AE}$ evaluation on the other hand. With advancing test duration, the dashed line is exceeded which indicates the border between stable and wear operation. Consequently, the scattering range spreads due to the chronologically differently pronounced wear processes of the tests.

3.4. Wear Characteristic. The above described correlation between the onset of wear and an elevated activity of $\mathrm{AE}$ is presented in Figure 12 in terms of a comparison of wear volume and AE energy of the JBA and RoD setting. Comparing the two settings, the observed AE energy is larger in the case of the RoD setting up to a factor of 2.2 depending on the elapsed test time.

The relation between the wear volume and the AE energy is fitted linearly in both cases resulting in a mean relative deviation between measured data and mean value of $11.1 \%$ in the case of the JBA setting whereas the deviation comes to $33.7 \%$ on average regarding the RoD setting. The presented linear relation is in accordance with reviewed references [2, 17]. The presented linear fits lead to points of intersection with the abscissa. These values number the measured AE energy, which correlate with operation free of wear. Since in the case of the RoD setting the deviating Test A leads to a reduced inclination of the fit, this threshold is underestimated. During this period, the $\mathrm{AE}$ are constant and show the described linear behavior as highlighted in Figure 11 when accumulated. From this threshold on operation is subjected to wear and the chronological run deviates from the linear run. These values hold for the particular system and the given test scenario.

The divergence in the resulting AE energy can be mainly attributed to the differing energy entry because of load, speed, and test duration. Additionally, the principle constructive differences of the test cells implicate differing AE wave propagation. However, in both cases, the same phenomenological linear wear behavior after the excess of the intrinsic threshold can be observed. Analogous to the tribometric test results in which relative changes of the $\mathrm{AE}$ signal indicated changes of the tribological behavior, it is necessary to consider the $\mathrm{AE}$ results phenomenologically and relatively as well regarding the comparison of the two test settings.

3.5. Surface Analysis. Light microscope and SEM analyses of the journal bearing and disc specimens' surfaces were conducted. The specimens were cleaned beforehand with isopropanol. The light microscope images were taken by using an Olympus type SZX12 stereomicroscope and an Olympus BX51M. Additionally, detailed surface analysis was conducted with Zeiss MA15 scanning electron microscopy (SEM), aided by energy dispersive X-ray (EDX) spectroscopy. The acceleration voltage was chosen constantly as $7.5 \mathrm{kV}$ for the EDX analysis. In Figure 13, row (a) depicts the light microscopic images of the chronological run of the journal bearing surface change in the course of the conducted tests on the JBA test setting. The topography contrast images of representative sections of the presented light microscopy images are depicted in row (b). Row (c) illustrates the 


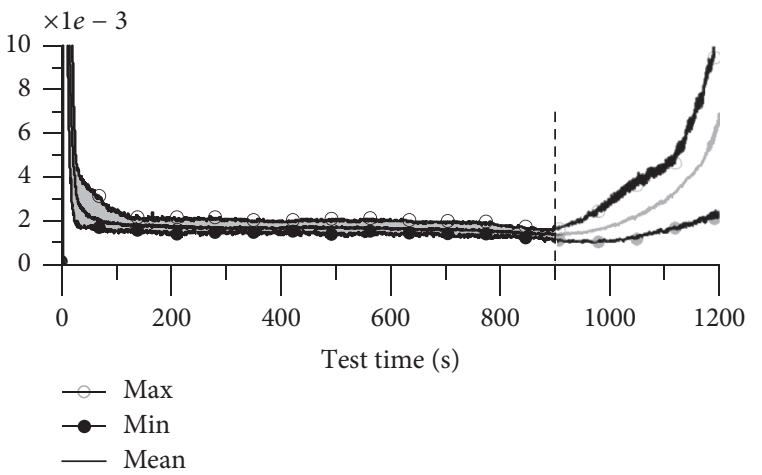

(a) JBA-COF [-]

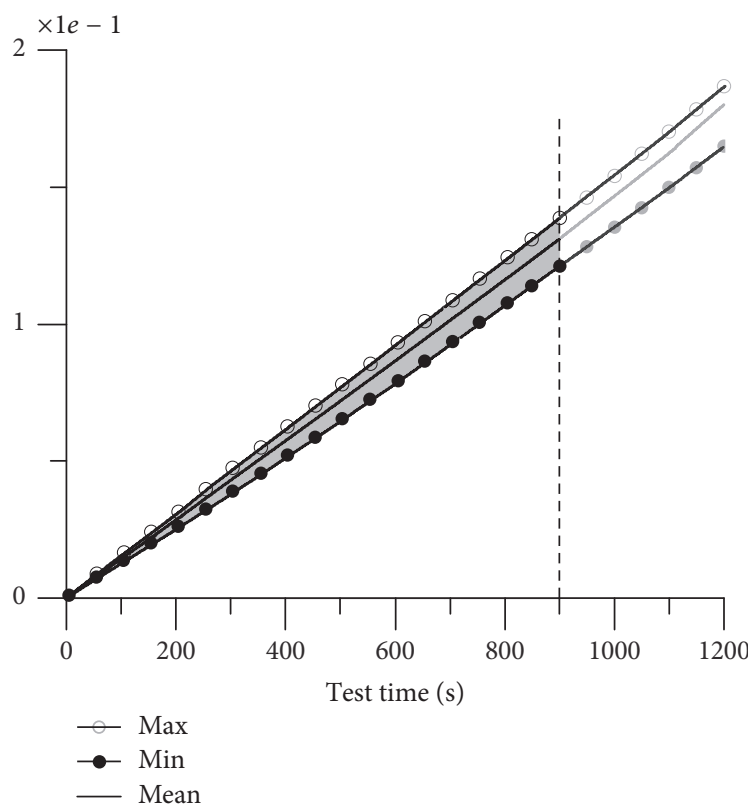

(c) JBA-AE energy $\left[\mathrm{V}^{2} \mathrm{~s}\right]$

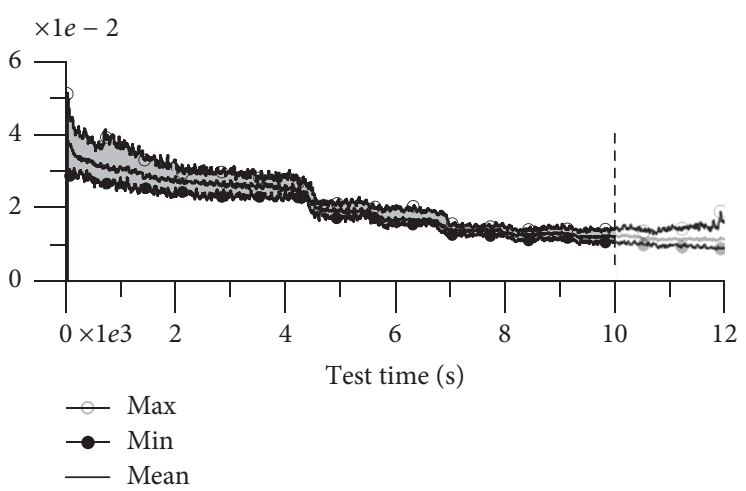

(b) RoD-COF $[-]$

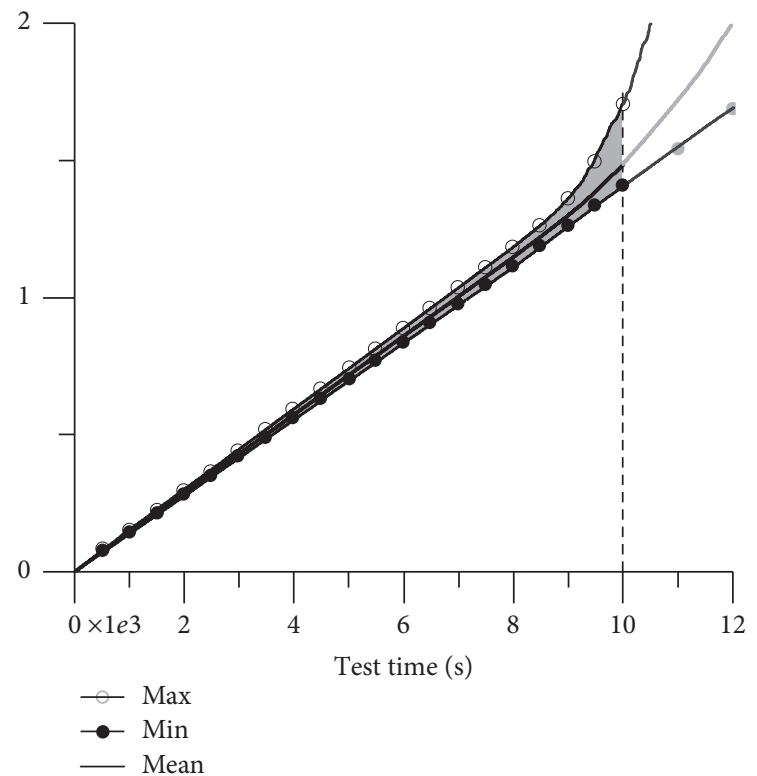

(d) RoD-AE energy $\left[\mathrm{V}^{2} \mathrm{~s}\right]$

FIGURE 11: Depiction of the minimum, maximum, and calculated mean run of the COF and AE energy for each test setting. The presented data serve as the basis for the evaluation of the methodology's reproducibility with respect to tribological processes and the corresponding AE measurement capability.

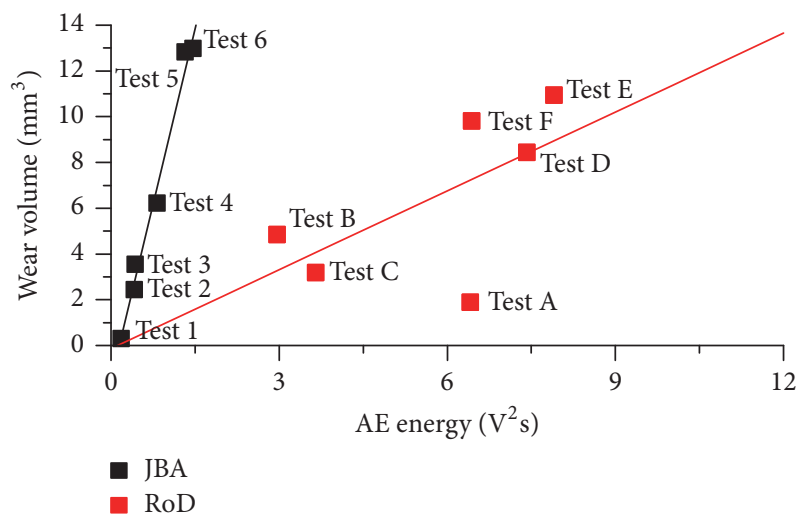

FIGURE 12: Correlation between measured wear volume and AE energy in case of the JBA and RoD setting. The data points are fitted linearly. corresponding material contrast images. The EDX analysis of marked spots 1-8 in row (c) can be found in Table 2 given in atomic percentage (at\%). The initial state shows small grooves resulting from the manufacturing process. The dim dark aluminium matrix is speckled with finely distributed spots of tin phases. Additionally, large spots of tin can be found on the surface. With the onset of direct solid contact between shaft specimen and journal bearing, the fine structure of the surface becomes destroyed and rills of larger magnitude occur. State 1 in Figure 13 illustrates this phenomenon and shows the topographic change towards larger rills and the change in material composition. Due to solid contact, the soft phase tin becomes active, melts, and is consequently consumed. Together with oxidized particles, tin phases become folded into the aluminium matrix. Grün et al. [40] describe this wear mechanism in detail. Continuous 

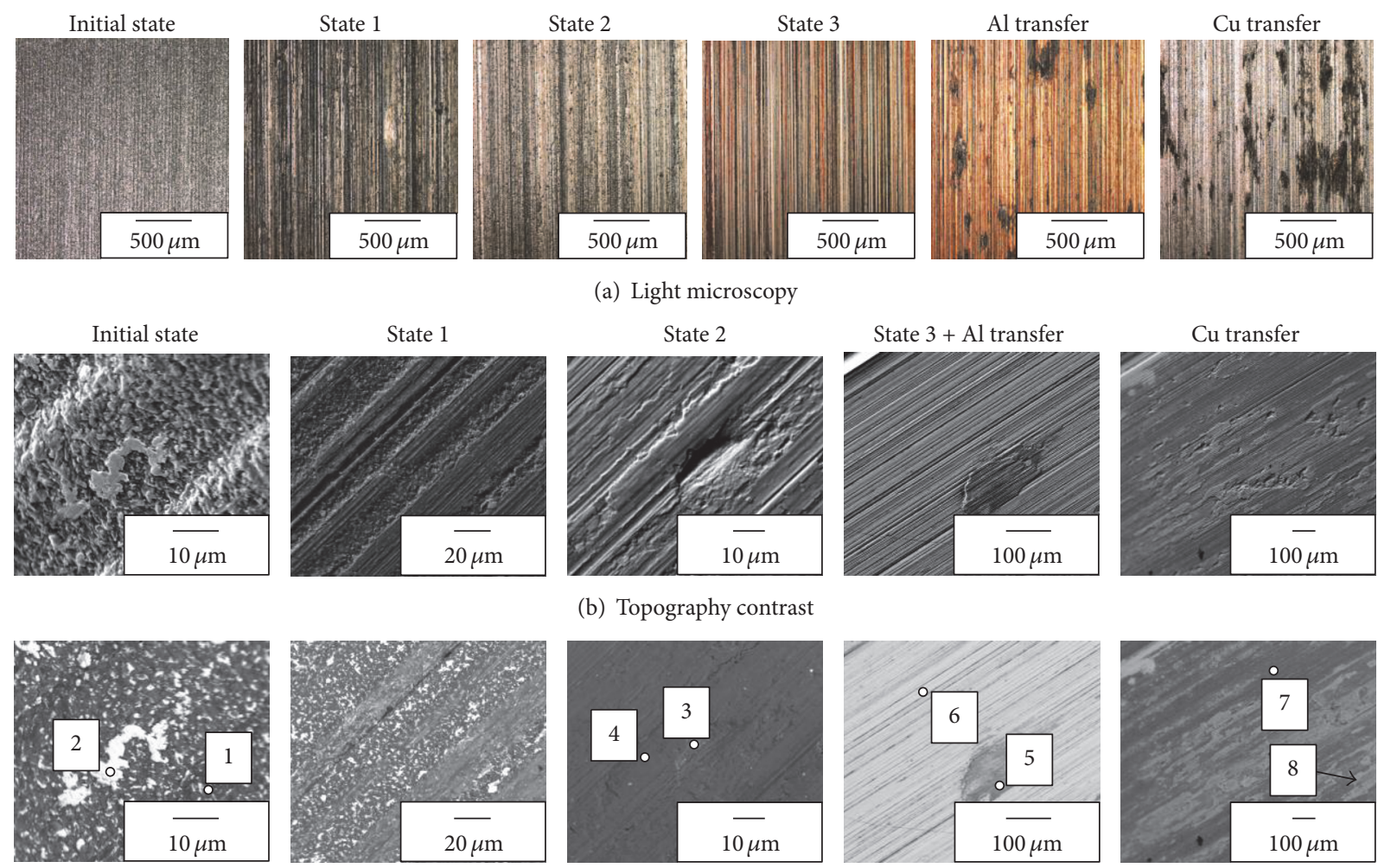

(a) Light microscopy
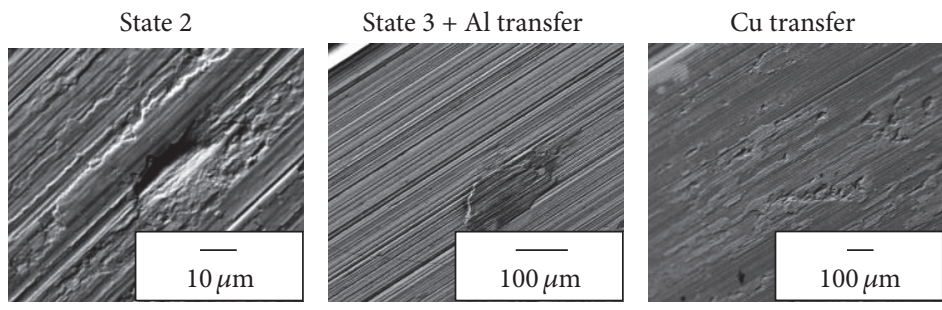

(b) Topography contrast
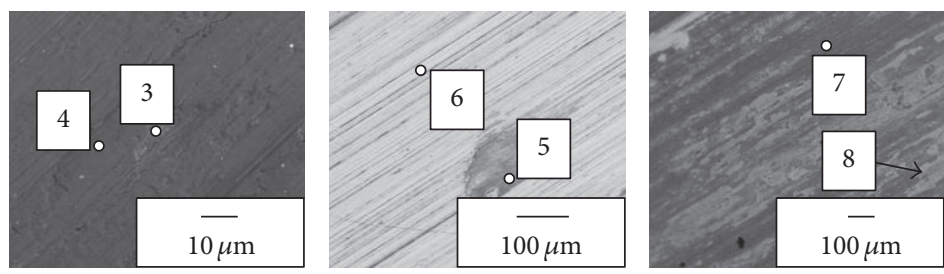

(c) Material contrast

FIGURE 13: Chronological run of journal bearing shell's surface degradation.

TABLE 2: EDX analysis corresponding to Figure 13 (EDX values obtained at $7.5 \mathrm{kV}$ and given in at\%).

\begin{tabular}{lcccccc}
\hline Spectrum & $\mathrm{C}$ & $\mathrm{O}$ & $\mathrm{Al}$ & $\mathrm{Cu}$ & $\mathrm{Sn}$ & $\mathrm{S}$ \\
\hline 1 & 5.6 & 2.6 & 90.2 & 0.5 & 1.2 & - \\
2 & - & - & 2.8 & - & 97.2 & - \\
3 & 5.1 & 18.2 & 74.1 & - & 2.6 & - \\
4 & 7.7 & 30.0 & 60.5 & - & 1.9 & - \\
5 & 7.2 & 36.0 & 33.5 & 19.6 & 2.8 & 0.9 \\
6 & 11.9 & 5.1 & 1.6 & 78.7 & 2.7 & - \\
7 & 4.9 & 12.9 & 75.7 & 3.8 & 2.8 & - \\
8 & 12.2 & 32.0 & 15.0 & 37.4 & 2.3 & 1.1 \\
\hline
\end{tabular}

solid contact results in the transmutation of the surface and the steady consummation of wear preventing tin phases, ultimately leaving the dark dim aluminium matrix (see State 2 in Figure 13). The remaining aluminium matrix exhibits reduced wear resistance. Consequently, break-outs resulting from adhesive bonding occur (see Figure 13, State 2). After the removal of the aluminium layer, the underlying bronze substrate comes to the fore (see State 3). In the final stage of wear, extensive material transfer occurs. Aluminium as well as copper particles of the contacting zones are dissolved from the surface layer and embedded again on the journal bearing's surface. The corresponding SEM analysis confirms the transfer of aluminium and copper.
The progress of wear in terms of surface degradation of the disc specimens (RoD setup) is depicted in Figure 14. Row (a) shows the light microscopy images providing an overview of the surface. The topography contrast images of a representative section of the presented images in row (a) are depicted in row (b). The corresponding material contrast images are illustrated in row (c). The bearing material exhibits the same elemental composition as the journal bearing specimens. Contrary to the journal bearing specimens, $\mathrm{AlCu}$ hard phases (see Position B) can be observed. Their distribution in the case of the journal bearing specimens is much finer due to the manufacturing process and is therefore not apparent. The aluminium matrix contains evenly distributed phases of tin; see Table 3 for EDX results of the marked positions A-L. Analogous to the presented progress of the journal bearing shells' wear, solid contact leads to the destruction of the even surface and the occurrence of larger grooves. Furthermore, the tribological load leads to the consumption of tin phases; see State 1 and State 2 in Figure 14. The initially elevated tin phases become reduced in height and smeared in sliding direction. The presented material contrast image of State 2 illustrates two areas of contact intensity. In the upper area, the contact was less pronounced leaving the surface in an intact state in which the remaining tin phases protect the aluminium matrix from wear. In the lower area, the more intense contact leads to the consumption of tin leaving only a thin film of tin on the surface. The subsequent State 3 represents the state of tin depletion. Due to the tribological 

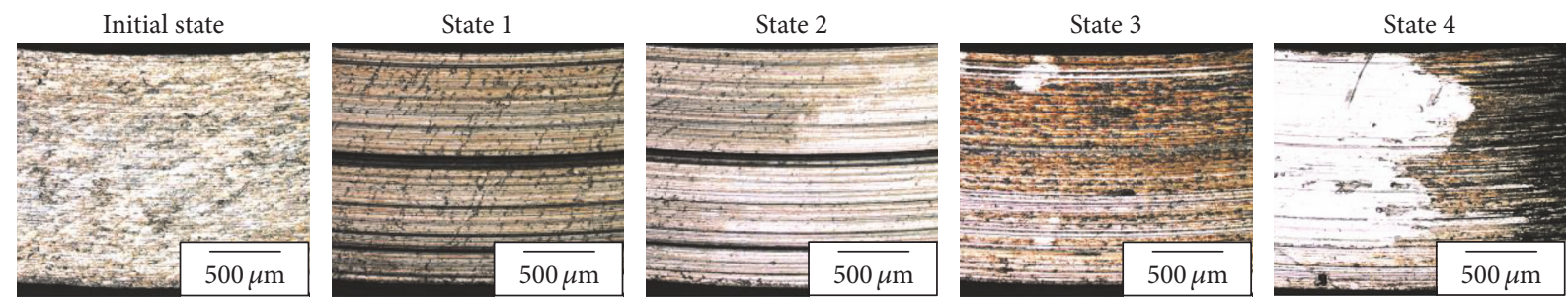

(a) Light microscopy
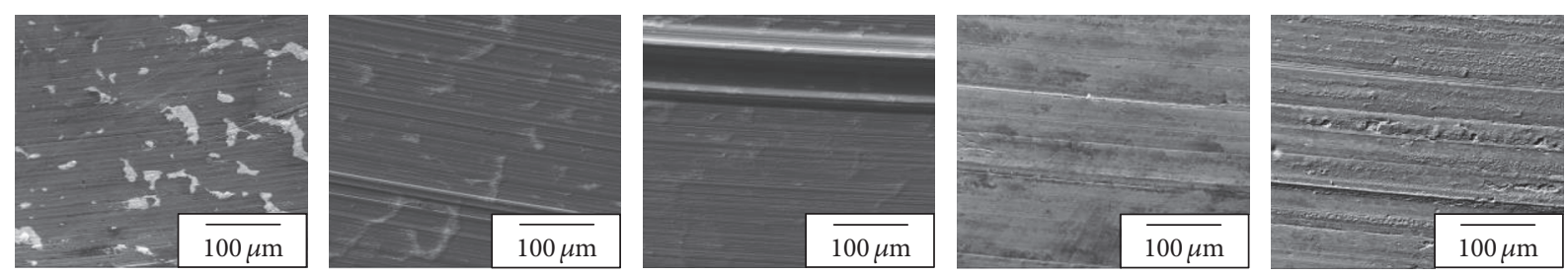

(b) Topography contrast
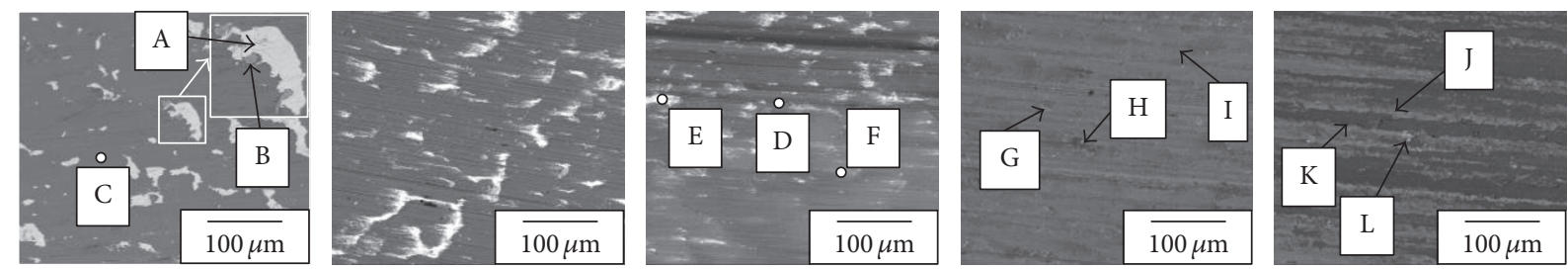

(c) Material contrast

FIGURE 14: Wear progress of RoD specimens.

TABLE 3: EDX analysis corresponding to Figure 14 (EDX values obtained at $7.5 \mathrm{kV}$ and given in at\%).

\begin{tabular}{lcccccc}
\hline Spectrum & $\mathrm{C}$ & $\mathrm{O}$ & $\mathrm{Al}$ & $\mathrm{Cu}$ & $\mathrm{Sn}$ & $\mathrm{Fe}$ \\
\hline $\mathrm{A}$ & - & 14.1 & - & - & 85.9 & - \\
$\mathrm{B}$ & - & 5.2 & 60.6 & 34.1 & - & - \\
$\mathrm{C}$ & - & 1.8 & 97.9 & 0.4 & - & - \\
$\mathrm{D}$ & 8.4 & 26.1 & 65.0 & 0.5 & - & - \\
$\mathrm{E}$ & 3.7 & 25.3 & 51.3 & - & 19.7 & - \\
$\mathrm{F}$ & 4.8 & 2.7 & 89.1 & 1.0 & 2.3 & - \\
$\mathrm{G}$ & 4.6 & 9.8 & 79.5 & - & - & 6.1 \\
$\mathrm{H}$ & 9.5 & 48.3 & 42.2 & - & - & - \\
$\mathrm{I}$ & 4.1 & 11.5 & 84.4 & - & - & - \\
$\mathrm{J}$ & 4.2 & 8.3 & 87.6 & - & - & - \\
$\mathrm{K}$ & 8.5 & 54.1 & 37.4 & - & - & - \\
$\mathrm{L}$ & 4.7 & 12.3 & 63.7 & - & - & 19.4 \\
\hline
\end{tabular}

load, the surface oxidized. In the absence of the protecting tin, the aluminium matrix exhibits an increased tendency to adhesive bonding resulting in material transfer and breakouts (see State 4 ).

The above described transmutations of the contacting surface can be correlated with the obtained tribometric results. With the depletion of tin, which provides low friction and prevents wear, the frictional losses as well as the wear tendency increase. The break of temporary adhesive bonding results in additional high frictional losses over a short period of time. The peaks in the COF run of the presented RoD test can therefore be connected to local adhesive bonding. With increasing amount of adhesive bonding as well as an increasing contact area, the relative sliding of the surfaces is additionally impeded leading to increased frictional losses as depicted in the presented tests of the JBA. The described stages of wear can be put into context to the AE wear correlation presented in Figure 12. While the material exhibits sufficient tin phases, the system operates in stable conditions. With the depletion of tin, the behavior transforms into unstable operation which consequently leads to increased $\mathrm{AE}$ and the excess of the AE energy threshold. The process of wear elapses according to the presented behavior in Figure 12 whereas the wear volume correlates linearly to the AE energy.

\section{Conclusions}

Condition monitoring with the help of $\mathrm{AE}$ is an effective possibility to evaluate tribological processes and to gain increased knowledge about the tribological system under investigation. Following the aim of enhancing the visualization capabilities of two tribological test rigs, AE measurement was applied yielding the following conclusions:

(i) The capability of the resolution of wear processes with help of the applied AE evaluation methodology was shown. While the AE signal remains constant and exhibits a continuous character during stable mixed friction operation, the intensity increases and the behavior changes to a discontinuous character with 
the onset of wear. Furthermore, a correlation between selected evaluation parameters (AE RMS, count rate, parameter $p$, energy, and standard deviation sigma) could be observed whereby the count rate exhibits restricted significance.

(ii) Besides the satisfying phenomenological reproducibility of the test rigs, a robust measurement behavior of the applied AE evaluation methodology could be shown which allows the differentiation between stable and unstable operation conditions as well as resolving the process of wear.

(iii) Dependent on the test rig, the dimensions of the AE evaluation parameter exhibit different orders of magnitude. The difference can be linked to the tribological contact, test rig, and position of sensor. Consequently, the evaluation method is not based on absolute quantities but on relative changes of the AE.

(iv) In interaction between tribometric results, optical surface analysis, wear parameter, and AE, it was possible to describe the process of wear comprehensively. A threshold, which links the accumulated AE to the onset of wear and a linear correlation between wear and $\mathrm{AE}$, was shown.

(v) By using the presented correlation between AE and wear, it was possible to create a master-wear curve which allows an in situ wear evaluation especially in the case of the JBA setting.

(vi) With the help of the application of AE, a further accompaniment of friction, sound, was made available which enlarges the existing measurement possibilities and enhances the informative value of tribological testing.

\section{Disclosure}

The authors are pleased to participate in further discussion and to provide further information where possible.

\section{Conflicts of Interest}

The authors declare that there are no conflicts of interest regarding the publication of this paper.

\section{Acknowledgments}

Financial support by the Austrian Federal Government (in particular from Bundesministerium für Verkehr, Innovation und Technologie and Bundesministerium für Wissenschaft, Forschung und Wirtschaft), represented by Österreichische Forschungsförderungsgesellschaft $\mathrm{mbH}$, and the Styrian and the Tyrolean Provincial Government, represented by Steirische Wirtschaftsförderungsgesellschaft $\mathrm{mbH}$ and Standortagentur Tirol, within the framework of the COMET Funding Programme is gratefully acknowledged. The authors would like to thank Miba Gleitlager $\mathrm{GmbH}$ for the support and provided specimens.

\section{References}

[1] M. Fritz, W. Burger, and A. Albers, "Schadensfrüherkennung an geschmierten Gleitkontakten mittels Schallemissionsanalyse," in Tribologie Fachtagung, vol. 1, pp. 30-1-30-9, 2001.

[2] V. Baranov, E. Kudryavtsev, G. Sarychev, and V. Schavelin, Acoustic Emission in Friction, vol. 53 of Tribology and interface engineering series, Elsevier, 2007, ISBN-13: 978-0-08-045150-3.

[3] E. Kannatey-Asibu Jr. and D. A. Dornfeld, "Quantitative Relationships for Acoustic Emission from Orthogonal Metal Cutting," Transactions of the ASME, vol. 103, pp. 330-340, 1981.

[4] K. Iwata and T. Moriwaki, "An Application of acoustic emission measurements to in-process sensing of tool wear," Annals of the CIRP, vol. 25, no. 1, pp. 21-26, 1977.

[5] A. Albers, H. T. Nguyen, and W. Burger, "Energy-efficient hydrodynamic journal bearings by means of condition monitoring and lubrication flow control," Insight: Non-Destructive Testing and Condition Monitoring, vol. 53, no. 8, pp. 431-433, 2011.

[6] J. I. Ukpai, R. Barker, X. Hu, and A. Neville, "Exploring the erosive wear of X65 carbon steel by acoustic emission method," Wear, vol. 301, no. 1-2, pp. 370-382, 2013.

[7] A. Hase, H. Mishina, and M. Wada, "Correlation between features of acoustic emission signals and mechanical wear mechanisms," Wear, vol. 292-293, pp. 144-150, 2012.

[8] M. Elforjani and D. Mba, "Detecting the onset, propagation and location of non-artificial defects in a slow rotating thrust bearing with acoustic emission," Insight: Non-Destructive Testing and Condition Monitoring, vol. 50, no. 5, pp. 264-268, 2008.

[9] D. Mba and R. B. K. N. Rao, "Development of acoustic emission technology for condition monitoring and diagnosis of rotating machines: bearings, pumps, gearboxes, engines, and rotating structures," Shock and Vibration Digest, vol. 38, no. 2, pp. 3-16, 2006

[10] J. L. F. Chacon, V. Kappatos, W. Balachandran, and T.-H. Gan, "A novel approach for incipient defect detection in rolling bearings using acoustic emission technique," Applied Acoustics, vol. 89, pp. 88-100, 2015.

[11] A. Choudhury and N. Tandon, "Application of acoustic emission technique for the detection of defects in rolling element bearings," Tribology International, vol. 33, no. 1, pp. 39-45, 2000.

[12] A. M. Al-Ghamd and D. Mba, "A comparative experimental study on the use of acoustic emission and vibration analysis for bearing defect identification and estimation of defect size," Mechanical Systems and Signal Processing, vol. 20, no. 7, pp. 15371571, 2006.

[13] C. James Li and S. Y. Li, "Acoustic emission analysis for bearing condition monitoring," Wear, vol. 185, no. 1-2, pp. 67-74, 1995.

[14] A. Morhain and D. Mba, "Bearing defect diagnosis and acoustic emission," Proceedings of the Institution of Mechanical Engineers, Part J: Journal of Engineering Tribology, vol. 217, no. 4, pp. 257272, 2003.

[15] Z.-Q. Zhang, G.-L. Li, H.-D. Wang, B.-S. Xu, Z.-Y. Piao, and L.$\mathrm{N}$. Zhu, "Investigation of rolling contact fatigue damage process of the coating by acoustics emission and vibration signals," Tribology International, vol. 47, pp. 25-31, 2012.

[16] S. Lingard and K. K. Ng, "An investigation of acoustic emission in sliding friction and wear of metals," Wear, vol. 130, no. 2, pp. 367-379, 1989.

[17] R. J. Boness, S. L. McBride, and M. Sobczyk, "Wear studies using acoustic emission techniques," Tribology International, vol. 23, no. 5, pp. 291-295, 1990. 
[18] S. Lingard, C. W. Yu, and C. F. Yau, "Sliding wear studies using acoustic emission," Wear, vol. 162-164, pp. 597-604, 1993.

[19] F. Saeidi, S. A. Shevchik, and K. Wasmer, "Automatic detection of scuffing using acoustic emission," Tribology International, vol. 94, pp. 112-117, 2016.

[20] Z. Karim, M. Z. Nuawi, J. A. Ghani, M. J. Ghazali, S. Abdullah, and N. I. I. Mansor, "Sliding wear evaluation of aluminum alloy (7075-T6) on hardened steel (AISI4340) via non-contact technique by I-kaz ${ }^{\mathrm{TM}}$ multi-level analysis," Wear, vol. 334-335, pp. 99-104, 2015.

[21] H.-J. Schwalbe, "Schallemissionsmessung an Gleitlagern zur Schadensfrüherkennung," in Fachtagung Instandhaltung '78, pp. 1-8, Deutsches Komitee Instandhaltung, Wiesbaden, Germany.

[22] A. Sturm and D.-I. S. Uhlemann, "Diagnosis of plain bearings by acoustic emission analysis," Measurement, vol. 3, no. 4, pp. 185-191, 1985.

[23] R. Stribeck, "Die wesentlichen Eigenschaften der Gleit- und Rollenlager," in Zeitschrift des Vereins deutscher Ingenieure 1902, vol. 46, Nr. 36, pp. 1341-1348, 1902.

[24] B. Ziegler, H.-J. Schwalbe, and A. Miszczak, Nachweis des Reibzustandes in Gleitlagern mit Hilfe der Schallemission, vol. 17, Kolloquium Schallemission, 2007.

[25] S. A. Mirhadizadeh, E. P. Moncholi, and D. Mba, "Influence of operational variables in a hydrodynamic bearing on the generation of acoustic emission," Tribology International, vol. 43, no. 9, pp. 1760-1767, 2010.

[26] M. Nagata, M. Fujita, M. Yamada, and T. Kitahara, "Evaluation of tribological properties of bearing materials for marine diesel engines utilizing acoustic emission technique," Tribology International, vol. 46, pp. 183-189, 2012.

[27] A. Hase, H. Mishina, and M. Wada, "Fundamental study on early detection of seizure in journal bearing by using acoustic emission technique," Wear, vol. 346-347, pp. 132-139, 2016.

[28] R. J. Boness and S. L. McBride, "Adhesive and abrasive wear studies using acoustic emission techniques," Wear, vol. 149, no. 1-2, pp. 41-53, 1991.

[29] J. Miettinen and V. Siekkinen, "Acoustic emission in monitoring sliding contact behaviour," Wear, vol. 181-183, part 2, pp. 897900, 1995.

[30] R. M. Douglas, J. A. Steel, and R. L. Reuben, "A study of the tribological behaviour of piston ring/cylinder liner interaction in diesel engines using acoustic emission," Tribology International, vol. 39, no. 12, pp. 1634-1642, 2006.

[31] H. S. Benabdallah and R. J. Boness, “Tribological behaviour and acoustic emissions of alumina, silicon nitride and SAE52100 under dry sliding," Journal of Materials Science, vol. 34, no. 20, pp. 4995-5004, 1999.

[32] H. S. Benabdallah and D. A. Aguilar, "Acoustic emission and its relationship with friction and wear for sliding contact," Tribology Transactions, vol. 51, no. 6, pp. 738-747, 2008.

[33] F. Grün, F. Summer, K. S. Pondicherry, I. Gódor, M. Offenbecher, and E. Lainé, "Tribological functionality of aluminium sliding materials with hard phases under lubricated conditions," Wear, vol. 298-299, no. 1, pp. 127-134, 2013.

[34] F. Summer, F. Grün, J. Schiffer, I. Gódor, and I. Papadimitriou, "Tribological study of crankshaft bearing systems: Comparison of forged steel and cast iron counterparts under start-stop operation," Wear, vol. 338-339, pp. 232-241, 2015.

[35] F. Grün, I. Gódor, W. Gärtner, and W. Eichlseder, "Tribological performance of thin overlays for journal bearings," Tribology International, vol. 44, no. 11, pp. 1271-1280, 2011.
[36] F. Grün, H. Krampl, J. Schiffer, J. Moder, I. Gódor, and M. Offenbecher, "Tribometric development tools for journal bearings - A novel test adapter," in Proceedings of the 5th World Tribology Congress, WTC 2013, pp. 1117-1120, ita, September 2013.

[37] F. Summer, F. Grün, I. Gódor, M. Offenbecher, and E. Lainé, "Tribometric performance of polymer overlays by contrast with other bearing materials," in Proceedings of the Symposium der ÖTG 2014, pp. 159-166, 2014.

[38] F. Grün, I. Gódor, and W. Eichlseder, "Test methods to characterise differently designed tribomaterials," Tribo Test, vol. 14, no. 3, pp. 159-176, 2008.

[39] H. N. G. Wadley, C. B. Scruby, and J. H. Speake, "Acoustic emission for physical examination of metals," International Metals Reviews, vol. 41, pp. 41-64, 1980.

[40] F. Grün, I. Gódor, and W. Eichlseder, "Fundamentals of optimizing aluminium-based journal bearing materials," Proceedings of the Institution of Mechanical Engineers, Part J: Journal of Engineering Tribology, vol. 223, no. 5, pp. 777-785, 2009. 


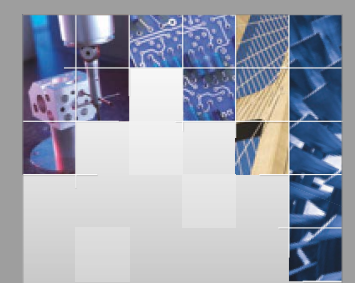

\section{Enfincering}
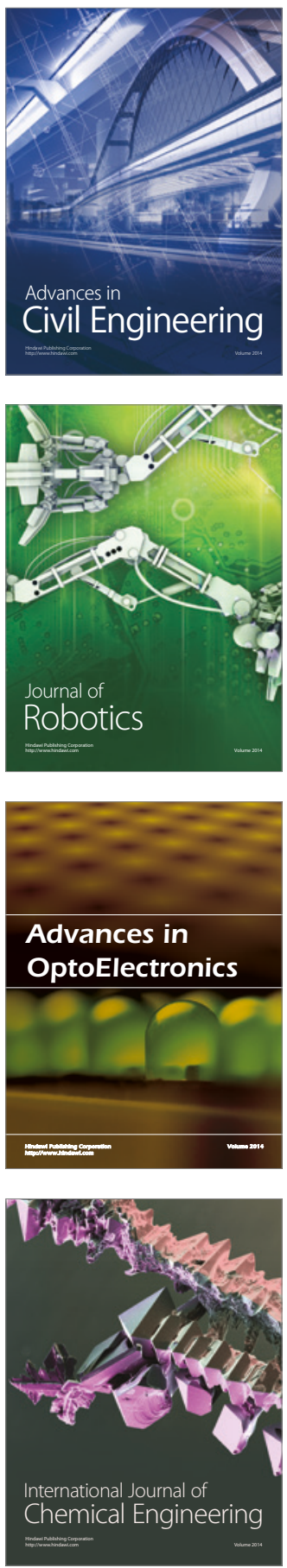

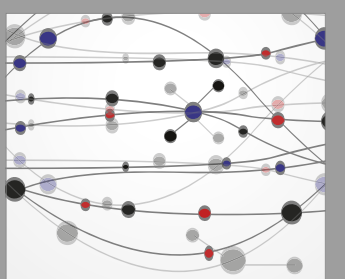

The Scientific World Journal

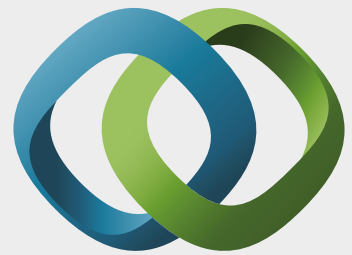

\section{Hindawi}

Submit your manuscripts at

https://www.hindawi.com
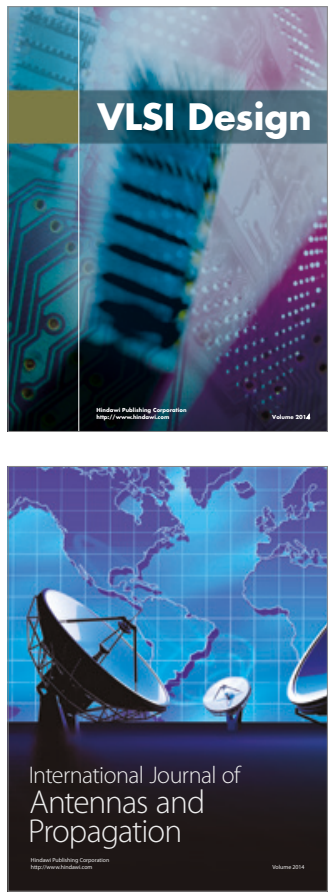

\section{Rotating}

Machinery
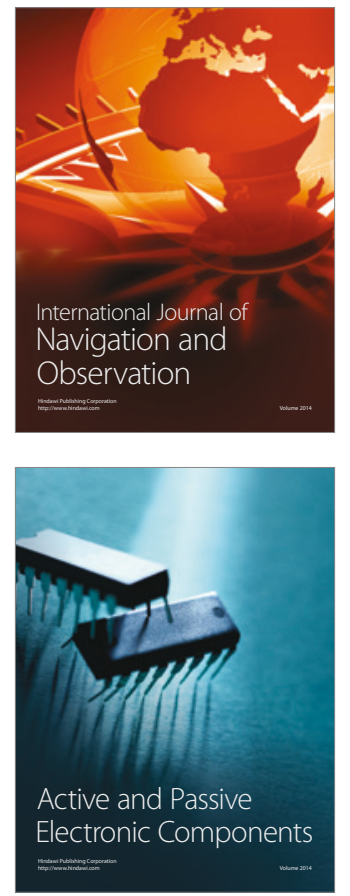
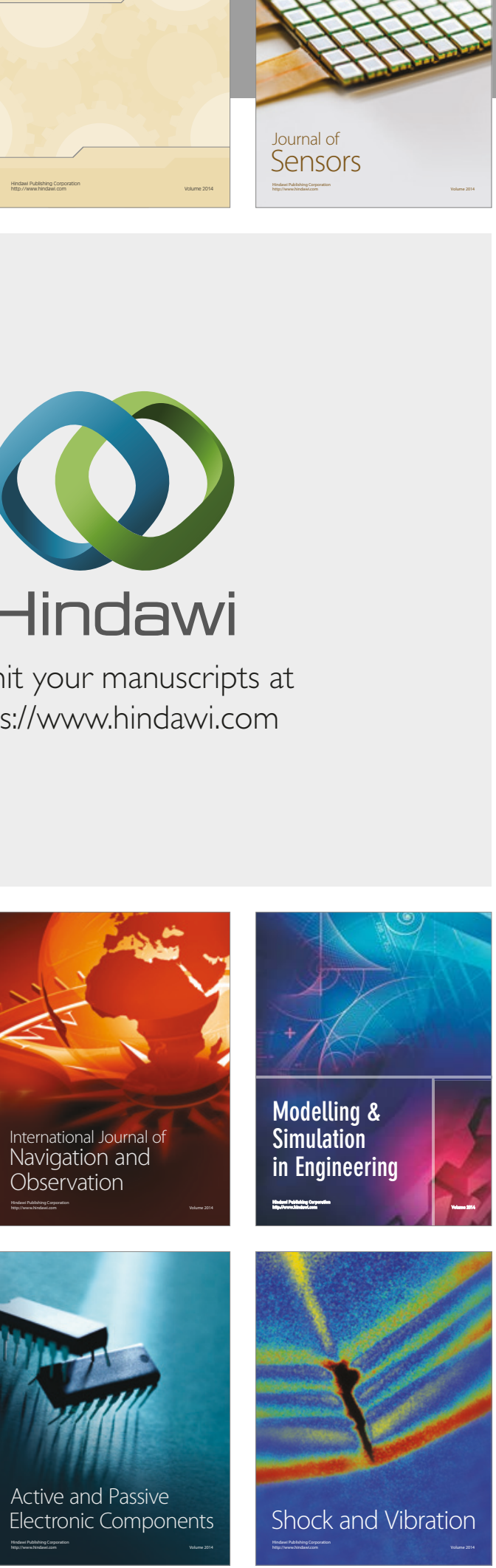
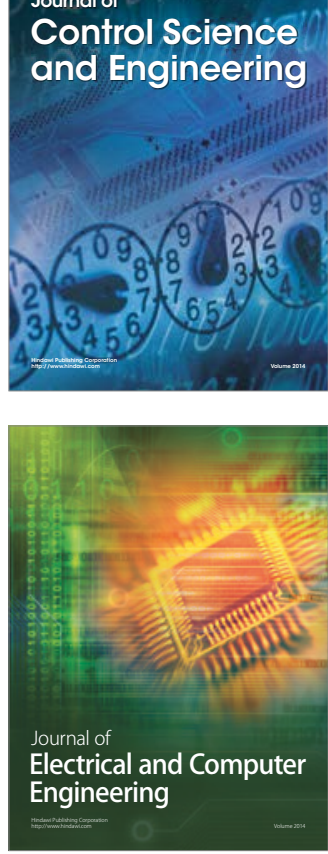

Distributed

Journal of

Control Science

and Engineering
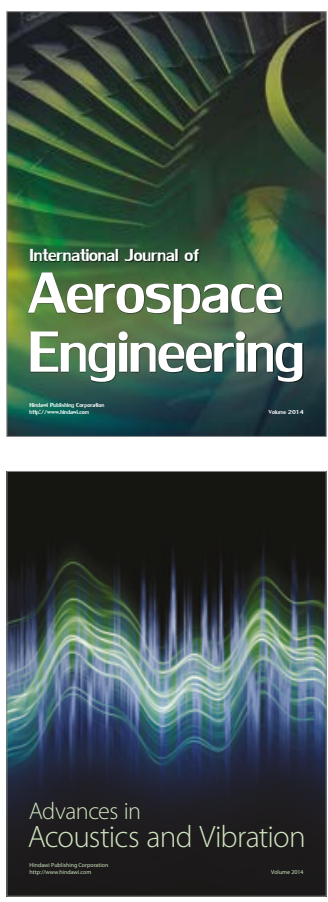

Sensor Networks 